OPEN ACCESS

Edited by:

Anna Grau Galofre,

Arizona State University, United States

Reviewed by:

Akos Kereszturi,

Hungarian Academy of Sciences

(MTA), Hungary

Giuseppe Sindoni,

Italian Space Agency (ASI), Italy

*Correspondence:

Manish Sharma

Manish.sharma@zu.ac.ae

${ }^{+}$These authors have contributed equally to this work

Specialty section:

This article was submitted to

Planetary Science,

a section of the journal

Frontiers in Astronomy and Space

Sciences

Received: 22 September 2021 Accepted: 08 December 2021

Published: 17 January 2022

Citation:

Howari FM, Sharma M, Xavier CM, Nazzal $Y$ and Alaydaroos F (2022) Atmospheric, Geomorphological, and

Compositional Analysis of Martian Asimov and Hale Craters: Implications

for Recurring Slope Lineae.

Front. Astron. Space Sci. 8:781166.

doi: 10.3389/fspas.2021.781166

\section{Atmospheric, Geomorphological, and Compositional Analysis of Martian Asimov and Hale Craters: Implications for Recurring Slope Lineae}

\author{
Fares M. Howari ${ }^{1 \dagger}$, Manish Sharma ${ }^{1 \dagger *}$, Cijo M. Xavier ${ }^{1}$, Yousef Nazzal ${ }^{1}$ and \\ Fatima Alaydaroos ${ }^{2}$
}

${ }^{1}$ College of Natural and Health Sciences, Zayed University, Abu Dhabi, United Arab Emirates, ${ }^{2}$ UAE Space Agency, Abu Dhabi, United Arab Emirates

Recurring slope lineae (RSL) are small, dark, seasonal albedo features lengthening down "warm" Martian steep slopes. Their origin has been attributed to both liquid and dry processes, hence representing one of the major open science questions on present day Mars. In the present study, we report a catalog of previous literature and newly added RSL sites making a total of 940 sites globally on Mars along with the detailed geological and compositional investigation of the Hale and Asimov craters with their RSL features. We also estimate temperature and atmospheric water abundances in the study area, which are two of the main factors to explain the origin and formation of RSL. The study found that the Asimov crater's local temperatures are high enough to allow either the melting of brines or deliquescence of calcium perchlorate and other salts during the HiRISE observation period and found the water vapor column to be nearly five times higher than those measured "before RSL appearance." This supports the theory of deliquescence as one of the mechanisms for the regolith-atmosphere interaction and RSL formation in the studied crater, which suggests that minerals absorb moisture from the environment until the minerals dissolve in the absorbed water and yield a solution. We also used compact reconnaissance imaging spectrometer for Mars-derived browse products for a compositional study associated with RSL features hosting craters and surface characteristics of Mars.

Keywords: Recurring Slope Lineae (RSL), HiRISE, atmosphere, geomorphology, mineralogy, mars

\section{INTRODUCTION}

Recurring slope lineae (RSL) are dark, narrow features that appear frequently on low-albedo steep slopes on Mars (McEwen et al., 2011; Hargitai and Kereszturi, 2015). Such features are around 40\% darker than nearby areas, originating from warm steep slopes and incrementally lengthening (McEwen et al., 2011). These features have three main properties: They gradually lengthen during warm seasons, disappear in colder periods, and recur annually (McEwen et al., 2011; McEwen et al., 2014; Stillman et al., 2014; Hargitai and Kereszturi, 2015). Sites of RSLs are continuing to be found in high-resolution images taken by the High-Resolution Imaging Science Experiment (HiRISE) onboard the Mars Reconnaissance Orbiter (MRO) (McEwen et al., 2011). The confirmed RSL sites have been noticed to lengthen, disappear, and reoccur, whereas candidate or potential sites 
lack evidence of these three noted features. These RSL sites generally have low-albedo exposed rocks. Previous studies on RSL in the equatorial region are most significant with warm seasons in Martian solar longitude (Ls) $=50^{\circ}-200^{\circ}$ (end of northern spring and whole summer season) on slopes facing north and in Ls $=200^{\circ}-290^{\circ}$ (mid northern autumn and early northern winter season) on southern facing slopes with a length of $100 \mathrm{~m}$ in Valles Marineris (McEwen et al., 2014).

RSL on Mars are hypothesized to originate from snow melting, deliquescence, dry flow, or shallow groundwater (Abotalib and Heggy, 2019). The RSL activity on sun-facing slopes, which are generally warmer, has convinced many to support the presence of volatile probably fresh water or brines (McEwen et al., 2011; Levy, 2012; Grimm et al., 2014; Ojha et al., 2014; Stillman et al., 2016). Experimental studies found that perchlorate and other salts in RSL could potentially form liquid brine via deliquescence with favorable environmental conditions (i.e., temperature, water vapor) (Zorzano et al., 2009; Gough et al., 2011; Fischer et al., 2014; Nuding et al., 2014; Nikolakakos and Whiteway, 2015; Nuding et al., 2015; Nuding et al., 2019). A Raman microscope equipped with an environmental cell was used to understand the water uptake properties of calcium perchlorate at RSL locations (Nuding et al., 2019), where the Raman spectra indicate that water uptake by salts may occur as relative humidity increases, which has directly impacted the atmospheric water cycle, causing particle growth, and thus triggering a dry granular flow (Nuding et al., 2019).

Other studies also have been conducted to investigate the source of water for RSL as water vapor from the Martian atmosphere through the deliquescence mechanism (McEwen et al., 2011; Leung and Rafkin, 2015; Rafkin et al., 2016; Pál and Kereszturi, 2020). The water vapor column on Mars varies according to numerous factors, including latitude and time of year. Another theory suggested is porous substrate wetting and capillary flow (Grimm et al., 2014). This suggests that, if a minimal amount of solution from the subsurface to the surface is found at RSL as a result of capillary draw, the surface volume of the solution reduces considerably, whereas a large solution volume could still take place in the subsurface (Grimm et al., 2014). However, the exact processes and origin of the hypothesized water remains uncertain.

Over the last decade, the level of information accessible about our neighboring planet and its history has increased dramatically, which enables us to further understand the geologic record of Mars in detail and gain insights into the evolving climate and geologic history of the planet. Several minerals were found, mapped with specific geological units, and used to comprehend geological processes. Alteration materials, including clay minerals, sulfates, carbonate, hydrated silica, and zeolite, have also been found on Mars, retaining evidence of the history of contact of water and rock in the crust (Ehlmann et al., 2008). The early Noachian units on Mars are shown to contain clay minerals, especially $\mathrm{Fe} / \mathrm{Mg}$ phyllosilicates and chlorite (Mustard et al., 2008), which are indicative of early weathering environments with liquid water. Fe/Mg clays in late Noachian-early Hesperian paleolakes were also found in fans and deltas (e.g., the Jezero, Eberswalde, and Holden craters), probably as both detrital sediments and in situ diagenesis (Grant et al., 2008; Goudge et al., 2015). Whereas hydrated mineralogy in Noachian or Hesperian areas are found to be widespread in the highlands, only a small amount is observed in the smaller northern lowlands (Ehlmann et al., 2008; Mustard et al., 2008; Munaretto et al., 2020). Recently, for many RSL sites, CRISM research has found spectral profiles that indicate an occurrence of hydrated oxychloride salts (chlorates and/or perchlorates) (Ming et al., 2014). A catalog of previous literature's sites and newly added RSL sites, making a total of 940 RSL sites, have been shown globally on Mars (Stillman et al., 2014) as shown in Figure 1A, whereas Figure 1B shows the confirmed RSL site observed in this study.

In this paper, we perform a detailed geomorphological and compositional analysis of the Asimov and Hale craters, two wellestablished study areas having confirmed RSL sites, and investigate the atmospheric conditions and their role in RSL activity to understand their formation. This paper is arranged as follows. We first detail the study area in Section 2. Then we present the data and methodology in Section 3. We discuss the results in Section 4, which consists of weather cycling, geomorphological study, mineralogical mapping, and image interpretation. Section $\mathbf{5}$ is the discussion. We end with a conclusion on geomorphology and composition of these two well-established RSL hosting crater sites.

\section{STUDY AREA}

Asimov is an $84-\mathrm{km}$ diameter crater $\left(47^{\circ} \mathrm{S}, 5^{\circ} \mathrm{E}\right)$ located in the heavily cratered plains in the southern ancient highlands of Mars (Morgan et al., 2011). It is distinguished from other craters in this region because it contains both a ring depression just within the crater rim and a pit near the center. Figure $\mathbf{2 A}$ is a Context Camera (CTX) mosaic image showing details of the internal part of the crater, which has an off-center depression and an annulus of valley systems. CRISM data observation footprints at Asimov crater are shown with red polygons. Figure 2B shows Mars Orbiter Laser Altimeter (MOLA) Digital Elevation Model (DEM) of the study region, showing total elevation difference in the crater of $3724 \mathrm{~m}$. The topographical analysis shows the crater's degraded rim in the northwest. Figure $2 \mathrm{C}$ shows the slope map of the study area, showing the RSL sites to be occurring around $22^{\circ}-36^{\circ}$ in the crater. A previous study by Morgan et al. (2011) shows the Asimov crater to be Noachian-aged, having material fill of Noachian-Hesperian age and a superimposed annulus of valleys encircling the margins of the crater floor. It is also regarded as one of the oldest exposed areas of the planet (Scott and Carr, 1978). There have been two confirmed RSL sites possessing RSL lengthening, fading, and recurrence properties, observed in the central pit and the southwest of crater. One candidate RSL site possessing two properties (lengthening + recurrence) and four RSL candidate sites having one property are observed in the Asimov crater HiRISE image as highlighted in Figure 2.

Hale crater is located at $35.7^{\circ} \mathrm{S}, 36.4^{\circ} \mathrm{W}$ in the vicinity of the junction of Uzboi Vallis and the northern edge of Argyre Basin 


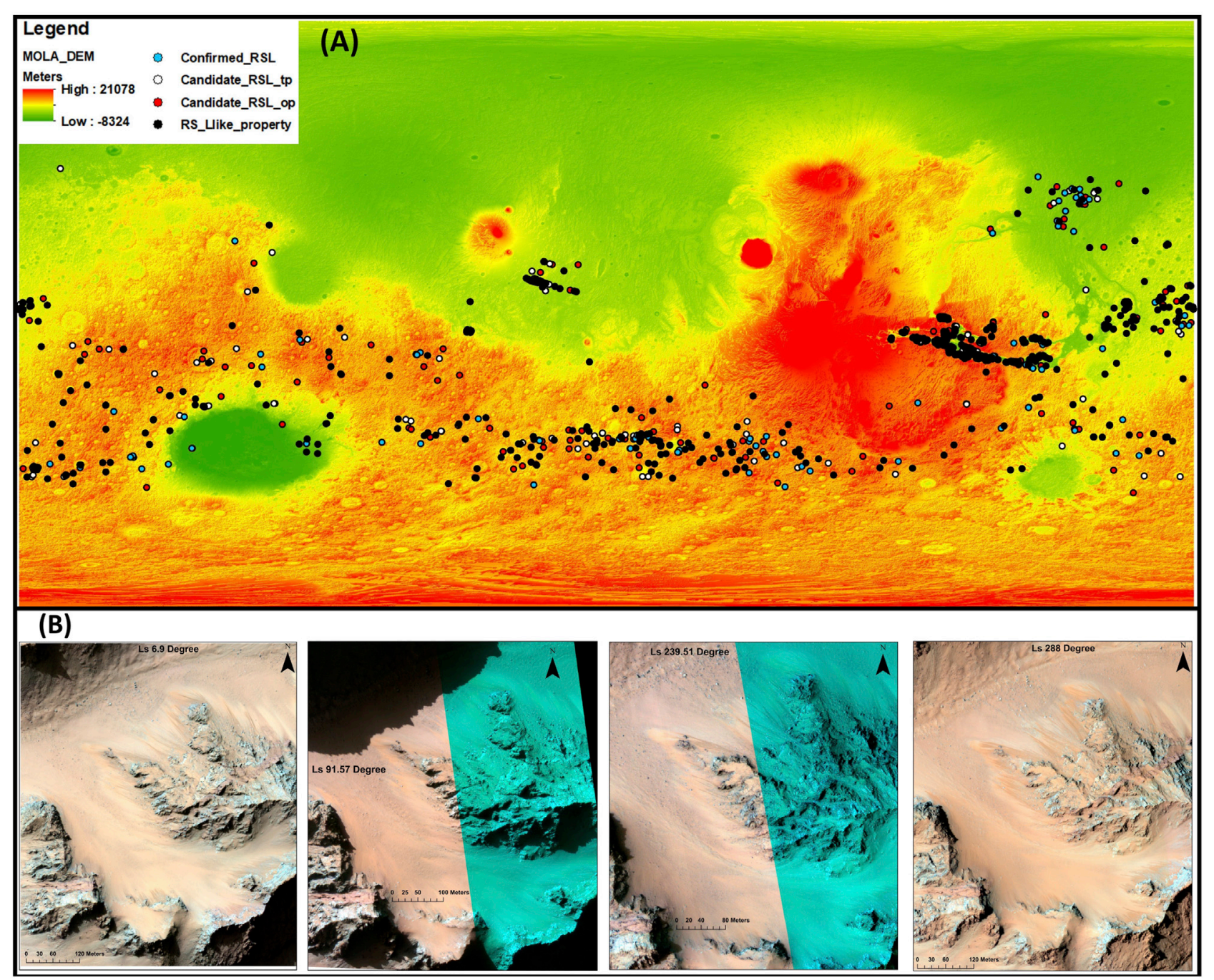

FIGURE 1 | (A) Updated RSL sites from previous literature (Stillman et al., 2014) and new identified sites globally on Mars. In legend, tp stands for RSL site having two properties of RSL, whereas op stands for site having one property of RSL, which are described as candidate RSL sites. (B) temporal observation of the confirmed RSL site in the study.

in the southern hemisphere with a north-south diameter of $125 \mathrm{~km}$ and east-west diameter of $150 \mathrm{~km}$. It is basically a complex crater with several terraces and a central peak (Melosh, 1989), estimated to be around $1 \mathrm{Ga}$ in age (Jones et al., 2011). It has a clearly defined rim and terrace structure in some parts north of the crater. One confirmed RSL site (lengthening + fading + recurrence) and two candidate RSL sites with two properties (lengthening + recurrence) of RSL have been observed in the central peak, whereas two further candidate RSL sites having one property are observed in crater's HiRISE image as shown. Figure 3A shows the CTX mosaic of Hale crater with several terraces and a central peak, whereas Figure 3B shows the MOLA DEM of Hale crater, revealing a total elevation difference of $5354 \mathrm{~m}$. Figure 3C shows the slope map of the Hale crater showing the RSL sites to be occurring around $14^{\circ}-28^{\circ}$ in the crater.

\section{DATA AND METHODOLOGY}

In this study, we used data from MRO HiRISE, CRISM, CTX, and Mars Global Surveyor (MGS) spacecraft MOLA data for comprehensive investigation of the RSL and their related atmospheric, geomorphological, and mineralogical parameters. The methodology used in this study is shown in Figure 4. With the help of its telescopic lens, HiRISE produces images with very fine detail. HiRISE data have a spatial resolution of $0.3 \mathrm{~m} /$ pixel (McEwen et al., 2011), which helped to investigate RSL activity in detail using HiVIEW: Image Viewer software specifically developed for handling HiRISE products. We also accessed the MOLA data set to investigate slope and elevation, using the slope tool in ArcGIS Software. MRO CTX has provided images that have been used to evaluate large-scale changes (tens of meters) to rapidly evaluate and record possible RSL activity (Malin et al., 2007). They have a spatial resolution of $\sim 5-6 \mathrm{~m} /$ 

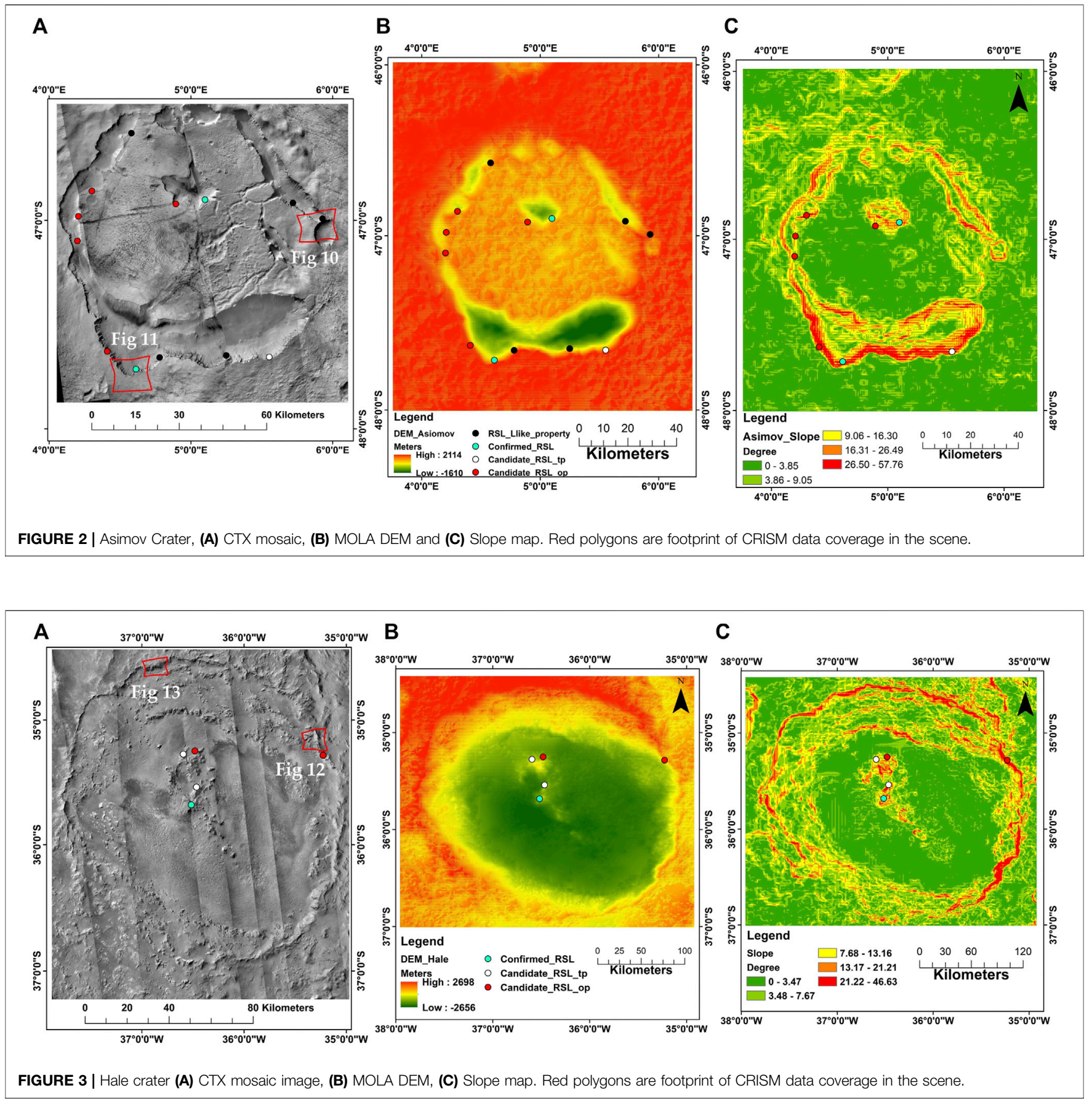

pixel (Murchie, 2007). The Mars Climate Database (MCD) version 5.3 web interface has been used to study the surface temperature and water vapor column of the same Martian year and date when the HiRISE image of the Hale and Asimov craters was taken. The MCD is a set of simulations of Mars atmosphere meteorological patterns and has been validated using observational data (Francois et al., 1999; Millour et al., 2018). Martian atmosphere researchers utilize this database as a source for scientific investigation and designing future Mars missions (Howari et al., 2020). The MRO CRISM data has been gathering visible and shortwave infrared surface spectra $(0.4-3.9 \mu \mathrm{m})$ since 2006 (Carter et al., 2013). Spectra from CRISM helps to understand the surface composition and identify the geological processes that have created iron and manganeserich facies, evaporite, and hydrated deposits of minerals (Ehlmann et al., 2008; Mustard et al., 2008; Munaretto et al., 2020). A qualitative multiparametric understanding of the surface mineralogy is now possible with the help of CRISM browse products. FAL, CHL, IC2, FEM, and FM2 browse products are derived to study the composition in the Hale 


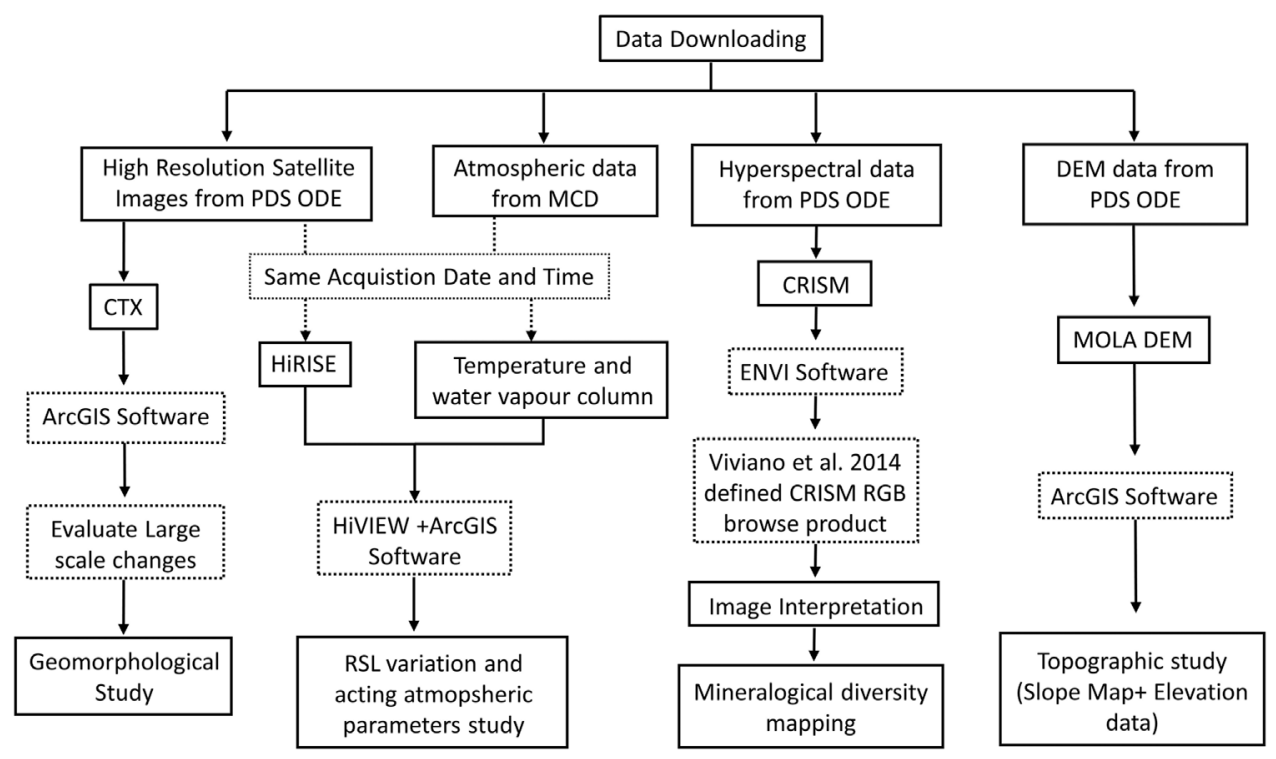

FIGURE 4 | Flow chart of data and methodology used in the study.

and Asimov craters. FAL is an improved infrared false color representation of the scene, whereas FEM and FM2 are used for mapping Fe minerals, particularly ferric and ferrous forms. IC2 shows information related to water or carbon dioxide frost or ice, whereas CHL shows information related to chloride deposits. The RGB band combination of these browse products and formulation defined by (Viviano et al., 2014) are as follows:

\subsection{RGB Band Combinations}

1. $F A L ~-~(R=R 2529 ; G=R 1506 ; B=R 1080)$.

2. FEM- $\left(\mathrm{R}=\mathrm{BD} 530 \_2 ; \mathrm{G}=\mathrm{SH600 \_ 2} ; \mathrm{B}=\mathrm{BDI} 1000 \mathrm{VIS}\right)$.

3. FM2- ( $\left.\mathrm{R}=\mathrm{BD} 530 \_2 ; \mathrm{G}=\mathrm{BD} 920 \_2 ; \mathrm{B}=\mathrm{BDI1000VIS}\right)$.

4. $\mathrm{IC} 2$ - $\left(\mathrm{R}=\mathrm{R} 3920 ; \mathrm{G}=\mathrm{BD} 1500 \_2 ; \mathrm{B}=\mathrm{BD} 1435\right)$.

5. $\mathrm{CHL}$ - ( $\mathrm{R}=\mathrm{ISLOPE} 1 ; \mathrm{G}=\mathrm{BD} 3000 ; \mathrm{B}=\mathrm{IRR} 2)$.

\subsection{Formulations}

1. BD530_2 $(0.53 \mu \mathrm{m}$ band depth $)=1-((\mathrm{R} 530)) /\left(\left(\mathrm{a}^{*} \mathrm{R} 614+\right.\right.$ $\left.\left.\mathrm{b}^{\star} \mathrm{R} 440\right)\right)$,

2. SH600_2 $(0.6 \mu \mathrm{m}$ shoulder height $)=1-\left(\left(a^{*} \mathrm{R} 533+\mathrm{b}^{\star} 716\right)\right) /$ ((R600)),

3. BD920_2 $(0.92 \mu \mathrm{m}$ band depth $)=1-((\mathrm{R} 920)) /\left(\left(\mathrm{a}^{*} \mathrm{R} 807+\right.\right.$ $\left.\left.b^{*} \mathrm{R} 984\right)\right)$,

4. BD1435 (1.435 $\mu \mathrm{m}$ CO2 ice band depth $)=1-((\mathrm{R} 1435)) /$ $\left(\left(a^{*} \mathrm{R} 1370+b^{*} \mathrm{R} 1470\right)\right)$,

5. BD1500_2 (1.5 $\mu \mathrm{m}$ H2O ice band depth $)=1-((\mathrm{R} 1525)) /$ $\left(\left(a^{*} \mathrm{R} 1367+b^{*} \mathrm{R} 1808\right)\right)$,

6. $\mathrm{BD} 3000(3 \mu \mathrm{m} \quad \mathrm{H} 2 \mathrm{O}$ band depth $)=1-((\mathrm{R} 3000)) /$ $((\mathrm{R} 2530 *(\mathrm{R} 2530 / \mathrm{R} 2210)))$,

7. ISLOPE1 (Spectral slope 1$)=1-((\mathrm{R} 1815-\mathrm{R} 2530)) /((\mathrm{W} 2530-$ W1815)),

8. IRR2 (IR ratio 2$)=((\mathrm{R} 2530)) /((\mathrm{R} 2210))$,

9. BDI1000VIS $=1 \mu \mathrm{m}$ integrated band depth; VNIR wavelengths.

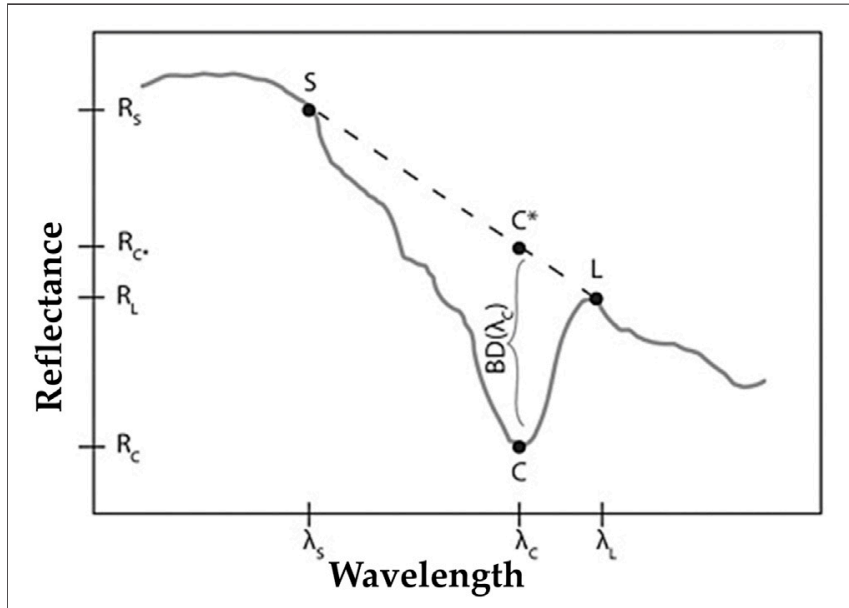

FIGURE $5 \mid \lambda c, \lambda s$, and $\lambda L$ derived to calculate $a$ and $b$ parameter used in CRISM browse product formulations: $\lambda_{c}$ is the reflectance at the center wavelength, $\lambda s$ is the reflectance value at shorter wavelength, and $\lambda \mathrm{L}$ is longer wavelength points along the continuum as shown in figure (Clark and Roush, 1984).

$\mathrm{R}^{* * *}$ indicated reflectance at particular wavelength $\mathrm{W}^{* * * *}(\mathrm{~nm})$. Calculation of spectral absorption depth is considered the most common parameter for mineralogical analysis, illustrated in Figure 5. Parameters a and b are the depth of the absorption (band depth), and are calculated (Clark and Roush, 1984) by

$$
a=1-b,
$$

where

$$
b=\frac{((\lambda c-\lambda s))}{((\lambda L-\lambda s))} .
$$


MCD data have a high level of confidence and have been widely validated. To retrieve the atmospheric water vapor content of the area, CRISM data could also have been evaluated (Smith et al., 2018). However, this did not occur in this study because of the limitation and unavailability of repeated data coverage. Previous study using CRISM data showed that the observed spurious signatures have systematic spectral noise behavior from CRISM ratioed spectra. Instead, with CRISM data, we are trying to correlate the current study with the RGB band combinations and atmospheric parameters.

\section{RESULTS}

\subsection{Weather Cycling and Geomorphology of Asimov and Hale Craters}

Shapes of RSL and their attributes are defined by (Wray et al., 2011), which occur in each spring and summer, particularly on falling sides at sharp angles and equatorial pointing toward southern slopes (Wray et al., 2011; Runyon et al., 2014). To support the formation of RSL in earlier hypotheses (Malin et al., 2007; Chevrier and Rivera-Valentin, 2012; Levy, 2012; McEwen et al., 2014; McEwen, 2015) in the identified craters requires additional atmospheric factors, i.e., abundance of water and temperature. These factors control the deliquescence-based processes. The water vapor column tells us about the total gaseous water contained in a vertical column of the atmosphere. As the relative humidity increases, visual growth and darkening are observed, which is caused by increased water uptake, confirmed by Raman spectroscopy equipped with an environmental cell (Nuding et al., 2019), which can be considered one of the triggering mechanisms of RSL.

In the Asimov crater, we studied surface temperature $(\mathrm{K})$ and water vapor column $\left(\mathrm{kg} / \mathrm{m}^{2}\right)$ at Ls $142.7^{\circ}$ (Figure 6C) for local Mars time 15:37 [the time of HiRISE-image ESP_028050_1330 acquisition (Figure 6A)] and at Ls $348.7^{\circ}$ (Figure 6D) for local Mars time 14:23 [the time of HiRISE image ESP_032586_1440 acquisition (Figure 6B)], showing the RSL variation in Figure 6. At Ls $142.7^{\circ}$ and Ls $348.7^{\circ}$, the temperature is found to increase from $158 \mathrm{k}$ to $261 \mathrm{~K}$ (inside crater), whereas the water vapor column increases from $0.0013 \mathrm{~kg} / \mathrm{m}^{2}$ to $0.0097 \mathrm{~kg} / \mathrm{m}^{2}$. This notable fivefold water vapor increase in the crater not only indicates regolithatmosphere interaction and high deliquescence potential in the surface and subsurface, it also suggests an active water cycle (Bhardwaj et al., 2019). These possibilities can be strengthened with corresponding HiRISE images with the same time of acquisition as the associated atmospheric parameters, which are shown in Figure 6. Thermal inertia could influence conditions for deliquescence outside the two target craters in their surroundings. RSL strongly favors the warmest times and places (although there are exceptions), suggesting but not requiring volatile activity. The other major observational argument for liquid water at RSL is the correlation between RSL activity and surface temperature through seasonality and/or slope orientation (McEwen et al., 2011; McEwen et al., 2014; Stillman et al., 2014; Stillman et al., 2016; Dundas et al., 2017; Stillman et al., 2017). Some observations point toward the possibility that RSL contains little or no liquid water. Edwards and
Piqueux (2016) found that the thermal signature of RSL at Garni crater was consistent with no water and placed an upper limit of $3 \%$ on the RSL water content. However, Stillman et al. (2017) point out that none of the thermal observations are synchronous with a definite observation of active lineae.

The HiRISE images show the change in Hale crater RSL activity, and accordingly, atmospheric parameters are also studied. The atmospheric parameters are studied for RSL activity at Ls $243.5^{\circ}$ (Figure 7C) for local Mars time 15:33 [the time of HiRISE image ESP_012663_1440 acquisition (Figure 7A)] and at Ls $329.5^{\circ}$ (Figure 7D) for local Mars time 14:17 [the time of HiRISE image ESP_032126_1440 acquisition (Figure 7B)]. In Hale crater at Ls $243.5^{\circ}$ and Ls $329.5^{\circ}$, the temperature is found to increase from $201 \mathrm{k}$ to $271 \mathrm{~K}$, whereas the water vapor column increases from 0.0017 to $0.0030 \mathrm{~kg} / \mathrm{m}^{2}$. Other RSL observations in the study area are shown in Table $\mathbf{1 .}$

The water vapor density could increase with temperature in the study area because of the impact of ice melting. Albedo is also expected to have an impact on the water vapor column. Schorghofer and Aharonson (2005) report in their modeling study that the average retreat of the ice due to the darkening could be $2.1 \mathrm{~cm}$ due to the albedo's impact. Because of this, the output of water vapor is a thousand times larger than the current atmospheric water vapor column abundance. Similarly, variations in albedo and changes in surface humidity cause the intake or release of water vapor and ultimately impact ice. Surficial changes of albedo or humidity may occur on relatively short time scales, driving changes in the subsurface ice distribution.

\subsubsection{Asimov Crater}

We explored the geomorphic record of the highly degraded Asimov crater situated within the Noachis terra. Since its emplacement in the Noachian, this impact crater has been substantially infilled by sedimentary materials like other Noachian aged craters. However, Asimov crater infill is unique because it displays an annulus with different valleys adjacent to the crater wall (Morgan et al., 2011). Asimov crater was emplaced within the hilly cratered unit (Nhc) of the Southern Highlands and is interpreted as the planet's oldest extensively exposed surface (Morgan et al., 2011). The crater surface is unique and intensely modified, loaded, and made up of a relatively flat unit, showing an annulus of disconnected valleys next to the inner sides of the crater rim. A collection of new, typical morphologies of alcoves, channels, and fans are superimposed on the lobate debris tongues (LDT). Detailed mapping of the various shapes of several LDTs also provides morphological evidence for viscous ice flows. Alcove, channel, and depositional fan are three morphological components used to describe gullies on Mars (Carter et al., 2013). Gullies are observed along the slope of the central depression systems and valleys although their external shape depends heavily on the slope part. South-facing gullies in Asimov crater are visibly developed and deeply engraved into the valley wall's steep sides, whereas the northern slope gullies (equator facing) show morphological and substantial differences with respect to south-facing (polar-facing) gullies. The dendritic network of tributaries in the polar-facing gullies is incomplete on the equator-facing area and is considerably less cut 


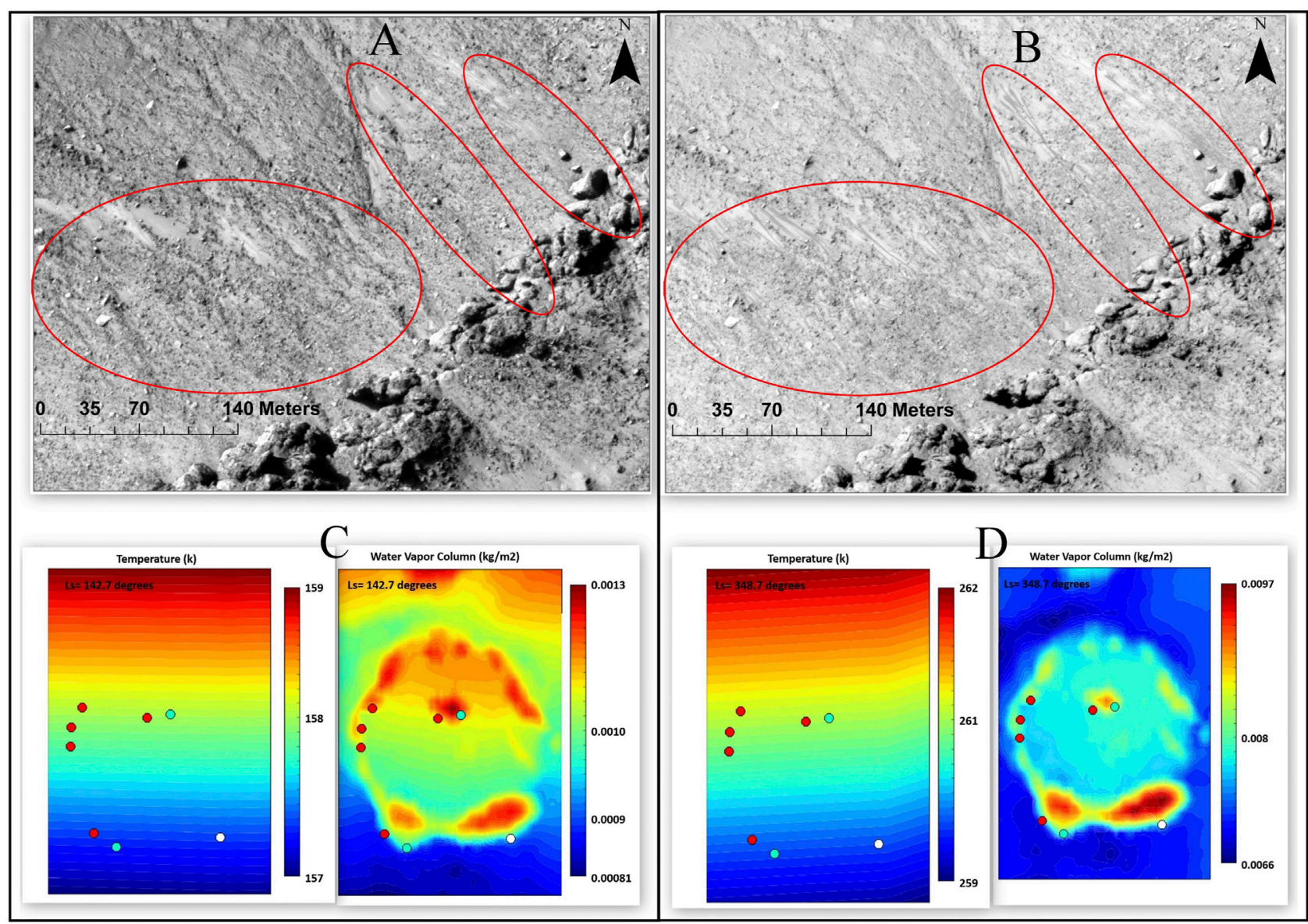

FIGURE 6 | (A) and (B) are HiRISE data of Asimov crater at Ls $142.7^{\circ}$ and Ls $348.7^{\circ}$ to see RSL variation in the image, whereas (C) and (D) are the associated atmospheric parameters acting at the same time of HiRISE data acquisition on the surface of Mars.

into the wall of the valley. They are smaller in size than the crater's major gullies. In the southern valley area, another form of gully is found, which is small in length and lies across the side of a dunecovered mountain. In this area, gullies consist only of channels. The distribution of gullies strongly indicates a climatic role. Sublimation to high obliquity levels of water and carbon dioxide ice from the polar areas would have also raised the atmospheric surface pressure (Costard et al., 2002) and atmosphere water vapor content (Mellon and Jakosky, 1995) and, thus, further facilitated the evolution of gullies. The detailed geological setting of Asimov crater, showing names of valleys and morphological parameters, is shown in Figure 8.

\subsubsection{Hale Crater}

To investigate the relation between Hale crater and its associated channels, the study explored the geomorphic features of the area mapped by Jones et al. (2011) utilizing data and images from the Thermal Emission Imaging System (THEMIS) (Christensen et al., 2004), the Mars Orbiter Laser Altimeter [MOLA, (Smith et al., 1999), the Mars Orbital Camera (MOC (Malin and Edgett, 2001)], the CTX, and the HiRISE. According to their geomorphological and thermophysical properties, Hale crater's major geological units are identified as Hale ejecta types 1 (He1) and 2 (He2), ponded and pitted surface materials $(\mathrm{Pp})$, rock formations $(\mathrm{Er})$, irregular crater clusters (Icc), preexisting channels (Pc), intracrater dunes (Iad), and intercrater dunes (Ied), which are mapped at 1:500,000 scale (Jones et al., 2011). Hale crater geomorphology is presented in Figure 9, showing the major units.

He1 stratigraphically overlays an exposed rock (Er) rough, blocky, resistant unit that makes up Hale's wall terraces, crater rim, and central peak complex. Colluvium overlays a cliff-like structure, and gullies arise on its sides where there is a sharp rise or fall. Er seems smoother and more mature and without angular sides. The blocky shape inside the crater may develop from high shock pressures that caused rock rupture near the site of impact. Icc are arranged into overlapped crater chains with broken twillweave patterns in the ejecta (Oberbeck and Morrison, 1973) radiating from Hale. These clusters of craters are known as secondary craters of Hale. They are mainly located northwest to northeast of Hale. In accordance with Herrick and Hessen (2006), the majority of the secondary craters are located inside the two identified ejectas. Channels inside Hale crater ejecta show a morphology regulated by the underlying topography, flowing up and around barriers. They are often immature and show 


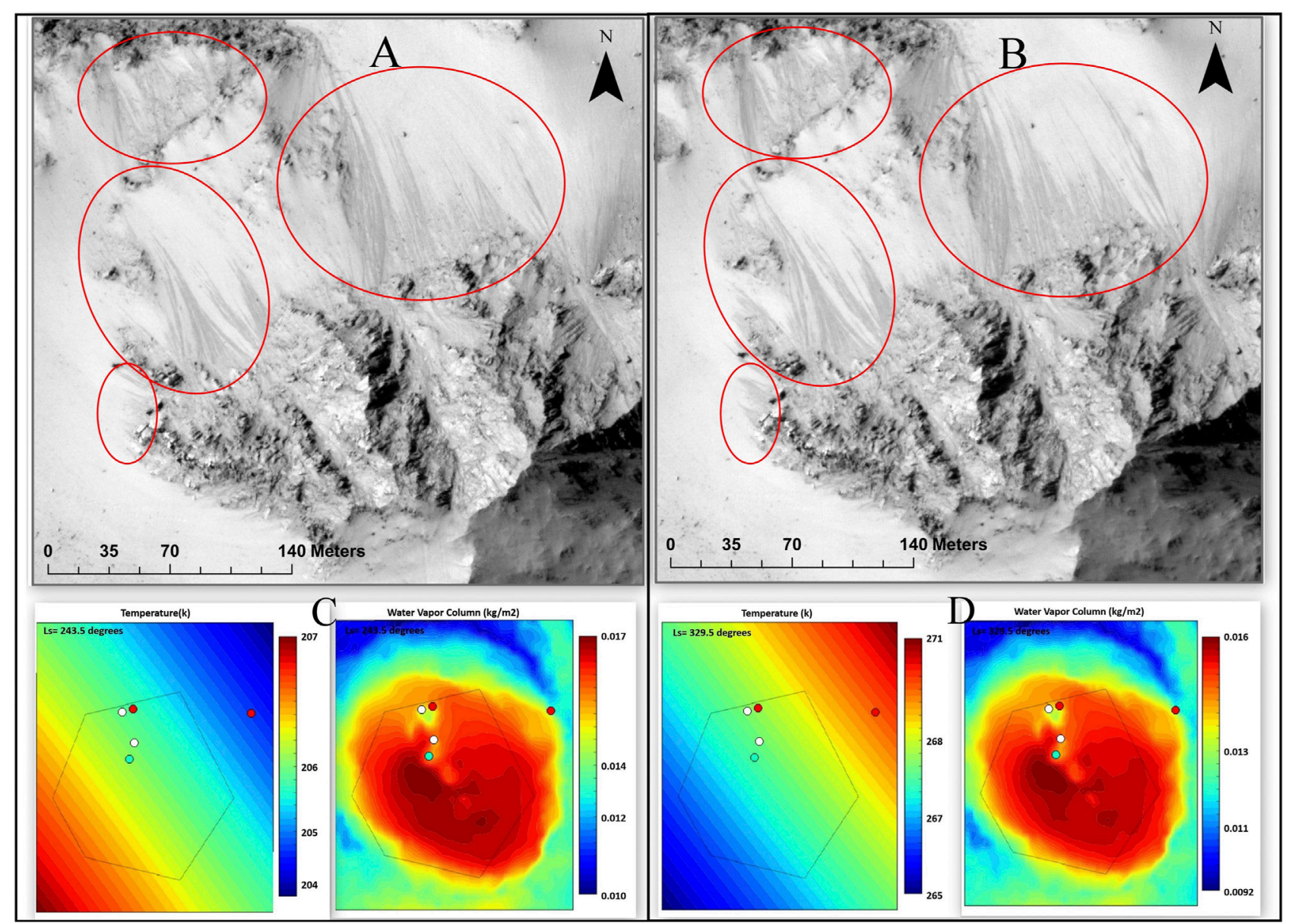

FIGURE 7 | (A) and (B) are HiRISE data of Hale crater at Ls $243.5^{\circ}$ and Ls $329.5^{\circ}$ to see RSL activity, (C) and (D) are the associated atmospheric parameters acting at the same time of HiRISE data acquisition.

TABLE 1 | RSL variation observed in Asimov and Hale crater.

RSL variation observed

in HiRISE image

Asimov Crater and Hale

Crater
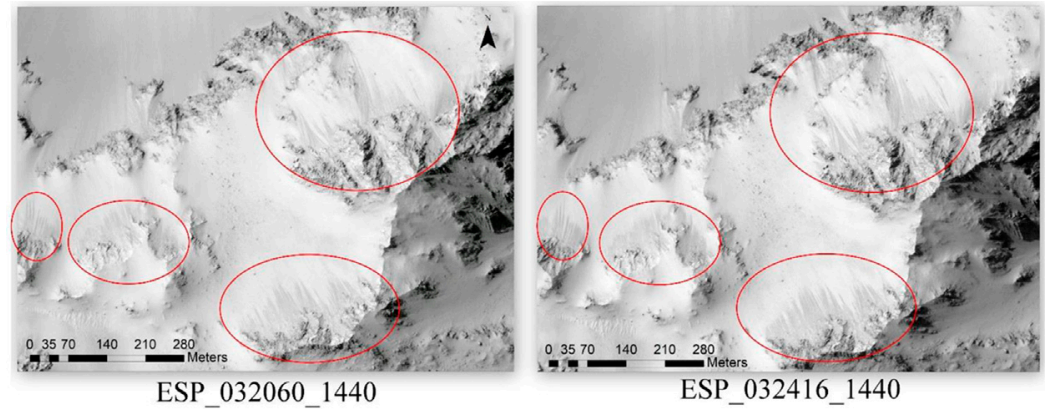

(Continued on following page) 
TABLE 1 | (Continued) RSL variation observed in Asimov and Hale crater.

RSL variation observed

in HiRISE image

Asimov Crater and Hale

Crater

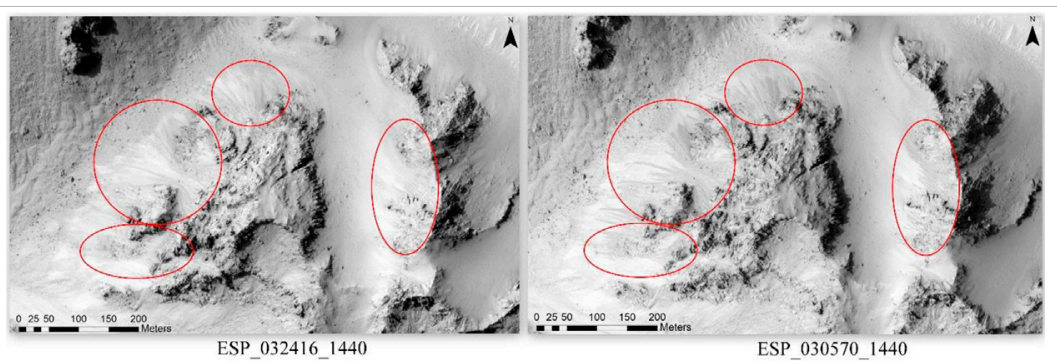

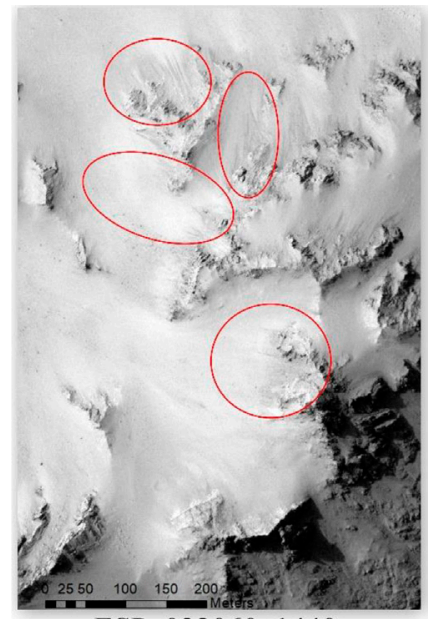

ESP_032060_1440

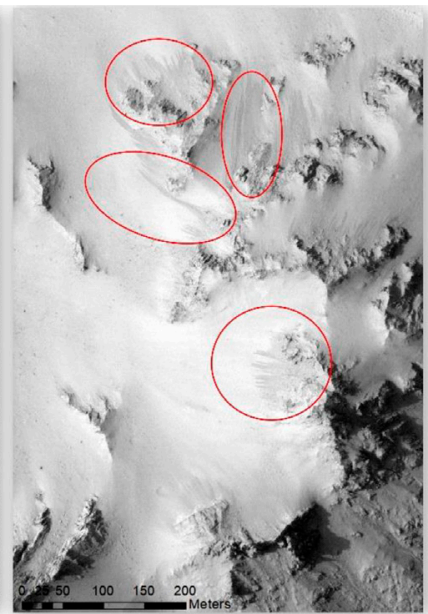

ESP $030570 \quad 1440$

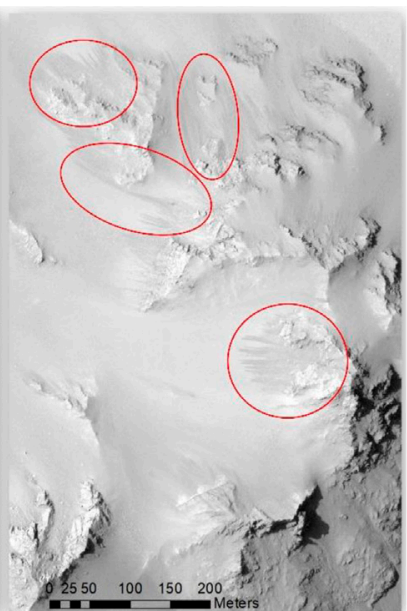

ESP_031203_1440
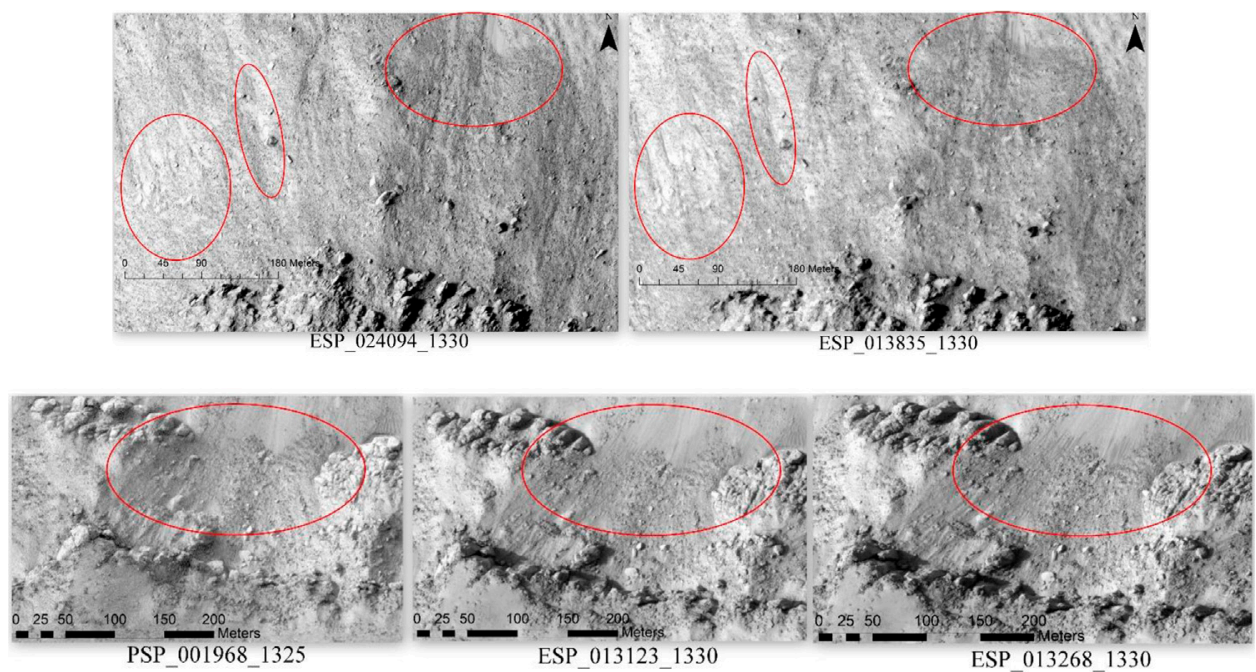

(Continued on following page) 
TABLE 1 | (Continued) RSL variation observed in Asimov and Hale crater.

RSL variation observed

in HiRISE image

Asimov Crater and Hale

Crater
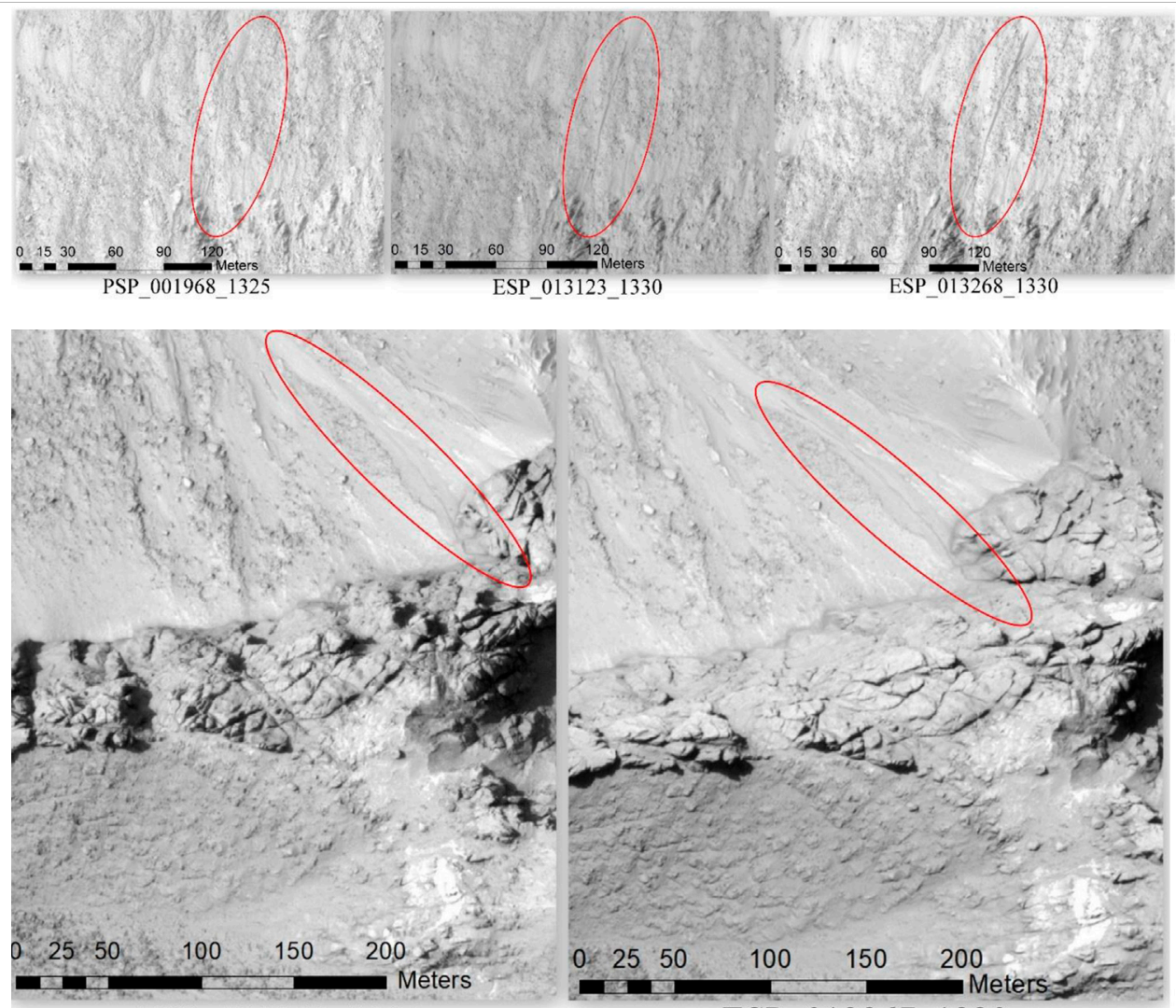

ESP_013334_1320
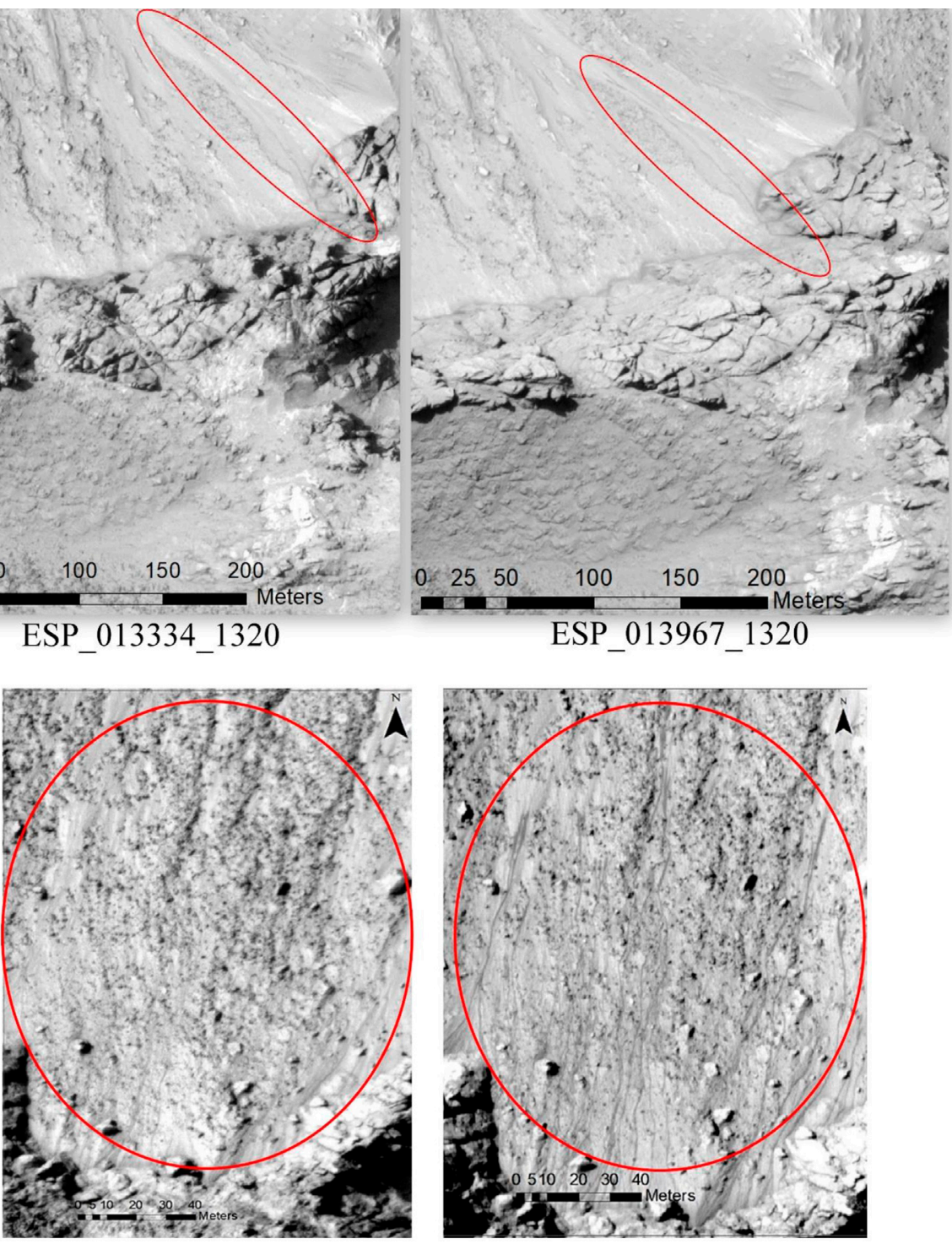

primitive branching patterns. Wide channels underlying Hale's

primary cavity than would have been possible otherwise. The Iad ejecta and, thus, predating it, are described as Pc. Hale ejecta used is a mapping of aeolian dunes inside the crater; the Ied is an area such channels as conduits, moving material further from the of dunes on the ground outside the crater cavities. 


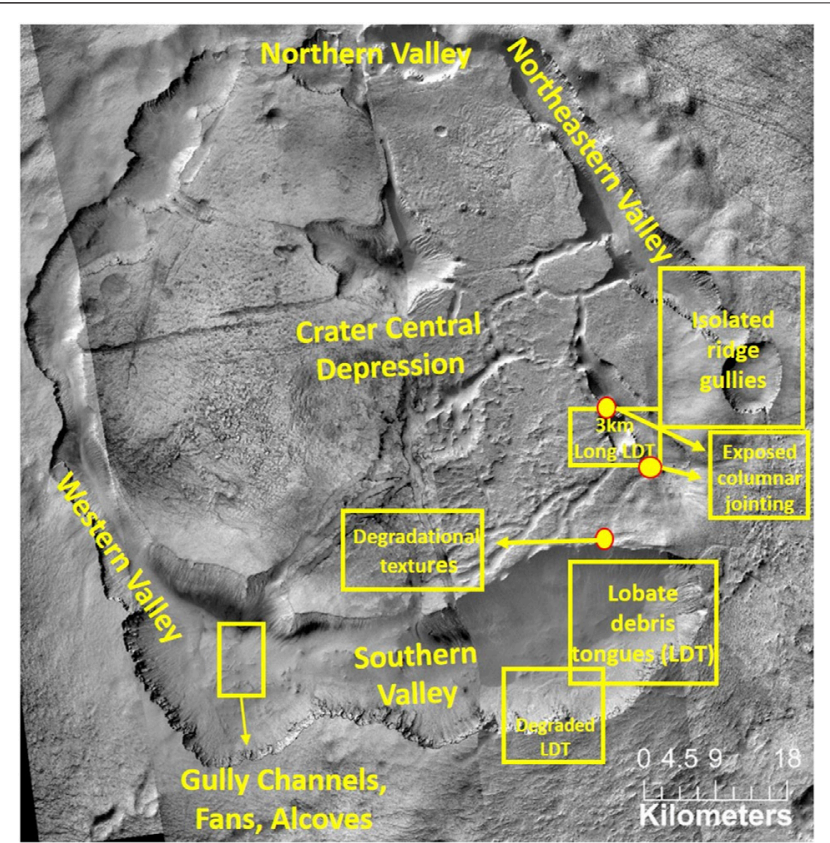

FIGURE 8 | Geological setting of Asimov crater, showing names of valleys and morphological parameters within Asimov crater. The background image is a mosaic image of CTX (having ID

D08_030239_1326_XN_47S355W,

D12_032019_1327_XN_47S354W, F09_039140_1327_XN_47S354W, F10_039694_1325_XN_47S355W, and P15_006860_1327_XI_47S354W).

\subsection{Mineralogical Study and Image Interpretation}

The CRISM instrument and high-resolution imagers have significantly sharpened our understanding of Mars' mineral analysis in terms of composition, setting, and global spatial distribution (Howari et al., 2021). CRISM data covers a small portion of the Asimov and Hale craters as shown by red polygons in Figure 2 and Figure 3, respectively. The strip of CRISM data also covers the candidate and confirmed RSL sites in Asimov crater. CRISM data browse products of the Asimov and Hale craters derived using the band combination and formulation (Viviano et al., 2014) are shown in Figures 10-13. CRISM images have been obtained from the Planetary Data System (PDS) at the most recent calibration level (MTRDR-Mapped Targeted Reduced Data Record). CRISM data covers a small portion of eastern and southwestern areas of Asimov crater for which footprints are shown in red polygons in Figure 2, and for the Hale crater, it is covering the Northern and Eastern parts of the crater as shown in red polygons in Figure 3.

Spectroscopic and lander data show large volcanic provinces composed of basalt and a surface that was hydrated $\left(\mathrm{OH}, \mathrm{H}_{2} \mathrm{O}\right)$, with possible traces of other alteration minerals (Soderblom, 1992; Ehlmann and Edwards, 2014). The FEM browse product is more responsive to ferrous and ferric absorption as well as slopes that are negative and with compacted dust texture or dust coatings (Viviano et al., 2014). Reddish colors in FEM browse product show the nanophase of crystalline ferric oxide, whereas green colors are a product of textural effects in the scene, and bluish colors are often more mafic surfaces and dust free. FM2 is particularly sensitive to nanophase ferric oxide and crystallineferric or ferrous, olivine with pyroxene minerals. In the FM2 browse product, reddish colors show nanophase ferric oxide presence, whereas green colors indicate coarser grained ironbearing minerals, especially low calcium-pyroxene, and bluish colors are mostly without dust or surfaces with more mafic minerals. The study explored IC2 browse products, in which $\mathrm{CO}_{2}$ frost or ice appears as blue colors displaying a sharp $1.435 \mu \mathrm{m}$ absorption (Viviano et al., 2014), whereas water ice or frost appears as green because of strong $1.5 \mu \mathrm{m}$ absorption. Reflectance at $3920 \mathrm{~nm}$ is used in the IC2 browse product to show ice-free surfaces as this particular reflectance is proxy for silicates, hence representing ice-free surfaces in red colors (Viviano et al., 2014). These were examined to learn more on the role of water or carbon dioxide frost or ice in the geodynamics of the Martian surface. CHL browse products reveal information related to chloride deposits revealed from the THEMIS sensor and hydrated mineral deposits. In the image, those surfaces have a relative positive near-infrared spectral profile and are comparatively dried up to represent the chlorides in blue colors, whereas the yellowish-to-green colors indicate hydrated minerals, especially phyllosilicates in the CHL browse product.

Asimov and Hale crater interpretations based on RGB color composite/browse products using the CRISM data are shown in Table 2. The minerals presented could give a proxy on the presence of water or their stability under Martian weather conditions. RSL are generally found in low-to-moderate albedo regions without significant dust deposits. CRISM data observation shows the investigated scene to have more mafic surfaces and be dust-free. However, dust is pervasive in Mars' atmosphere, and thin or partial coatings are likely to occur on most surfaces, sometimes due to air fall. In general, during autumn and early winter (Ls $\sim 0^{\circ}-140^{\circ}$ ), the content of atmospheric dust decreases to its lowest values (Lemmon et al., 2015). Outside the polar cap edge, dust storm activity is reduced at that time (Kass et al., 2016). Surface lifting inferred to be caused by dust-devil activity is principally observed in the northern hemisphere (Cantor et al., 2006). For RSL, this period also corresponds to both limited activity and activity favoring the northern hemisphere: gentle lengthening for the most active northern sites (Stillman et al., 2016) and modest activity compared with other Ls at some equatorial sites (Hargitai and Kereszturi, 2015). Fading compatible with progressive dust settling is also observed at that time at equatorial or southern latitudes.

\section{DISCUSSION}

In this section, detailed geomorphological and compositional analysis is presented with consideration about the atmospheric parameters with the aim to investigate the origin of RSL present in these craters. Characterizing the details of temperatures in the study area by giving humidity values or daily cycling of temperature and humidity is difficult. Because the unique 


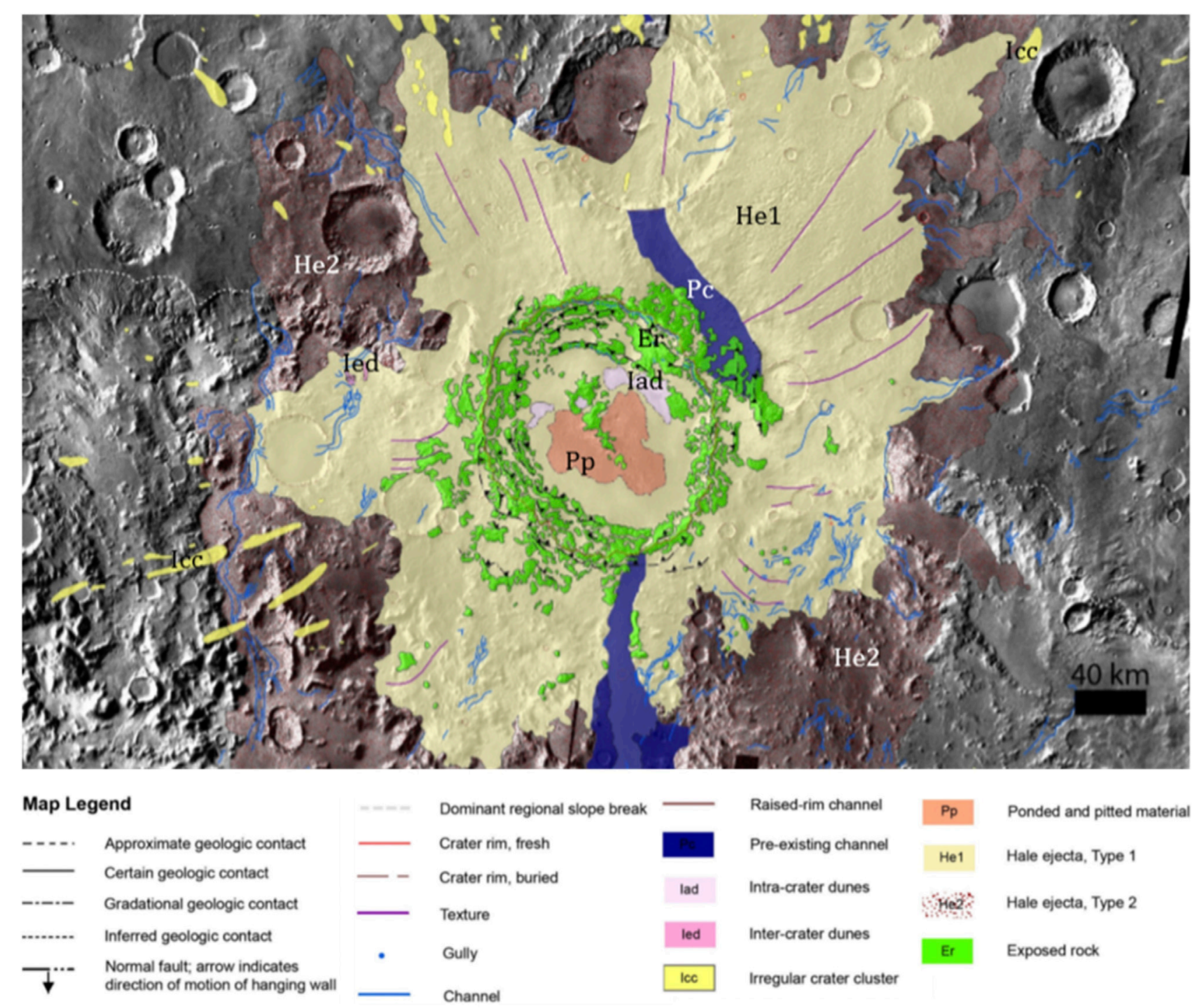

FIGURE 9 | Hale crater geomorphology and its associated ejecta mapped by (Jones et al., 2011). Uzboi Vallis is indicated by navy blue colors.

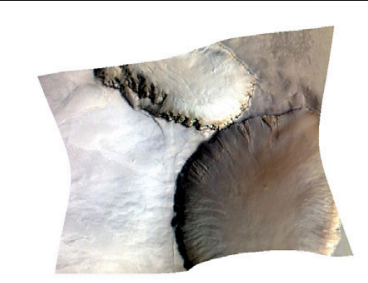

FAL

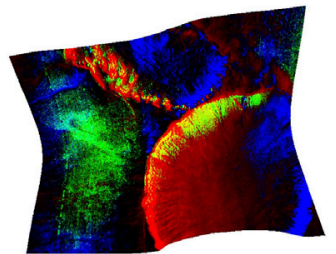

CHL

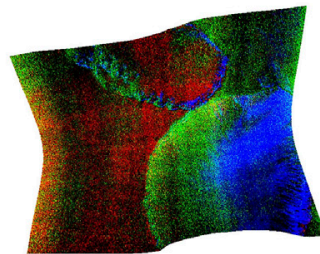

FEM

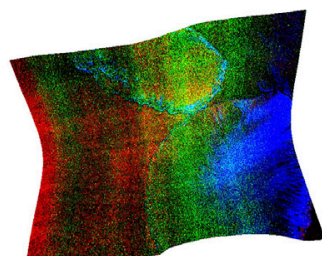

FM2

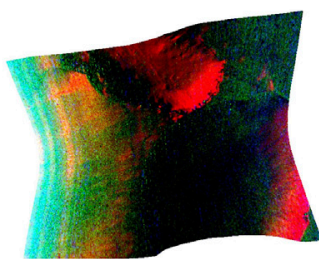

IC2

FIGURE 10 | CRISM Browse products results in eastern Asimov Crater. Footprints of data are shown with red polygons in Figure 2

temporal behavior of RSL was not recognized in earlier research, the HiRISE images were used for purposes other than deducing the annual cycling of temperature and humidity. Literature review indicates that RSL could be dry or only transiently wet at very cold temperatures (McEwen, 2018; Rivera-Valentín et al., 2020). However, other work suggests that putative deliquescent 


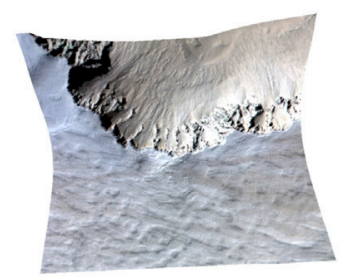

FAL

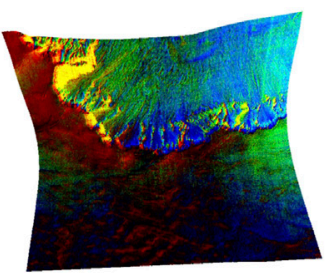

CHL

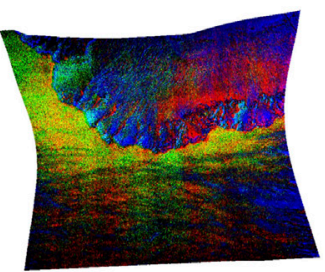

FEM

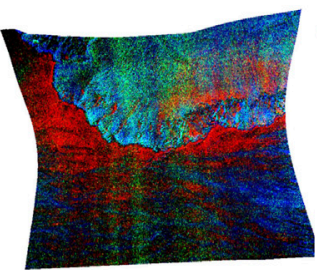

FM2

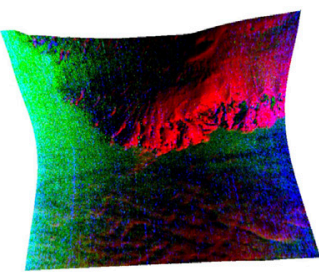

IC2

FIGURE 11 | CRISM Browse products results in South-West Asimov Crater. Footprints of data are shown with red polygons in Figure 2.

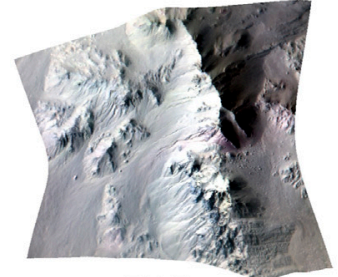

FAL

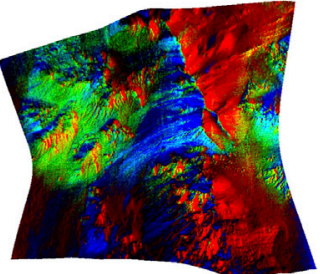

CHL

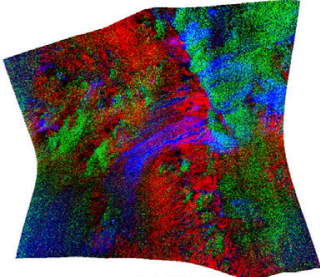

FEM

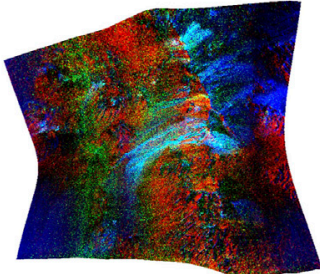

FM2

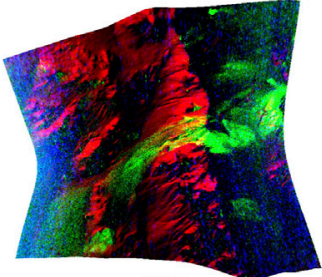

IC2

FIGURE 12 | CRISM Browse products results in Eastern Hale Crater. Footprints of data are shown with red polygons in Figure $\mathbf{3}$

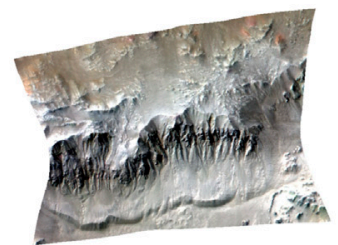

FAL

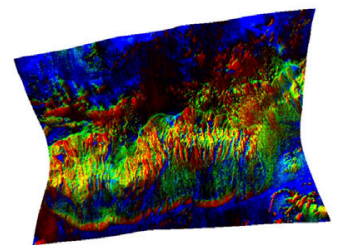

CHL

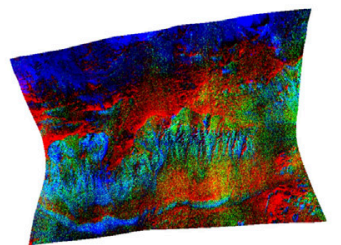

FEM

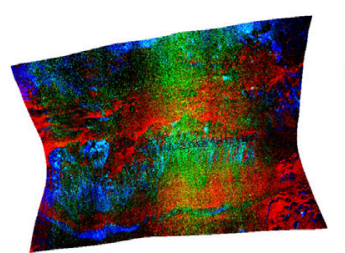

FM2

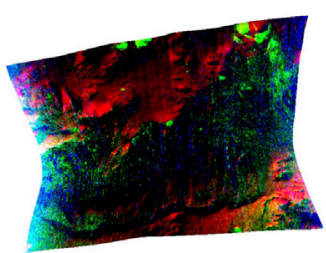

IC2

FIGURE 13 | CRISM Browse products results in Northern Hale Crater. Footprints of data are shown with red polygons in Figure 3.

TABLE 2 | Asimov and Hale Craters interpretation made on the basis of summary products derived using CRISM data as RGB color composite/browse product.

\begin{tabular}{|c|c|c|}
\hline S.No. & Strip location & Composition \\
\hline 1 & Eastern Asimov Crater & $\begin{array}{l}\text { Coarse-grained Fe (particularly low calcium pyroxene), hydrated mineral (phyllosilicates), chlorides, ice-free and more mafic } \\
\text { surface (Figure 10) }\end{array}$ \\
\hline 2 & South-West Asimov Crater & $\begin{array}{l}\text { Water ice or frost, chlorides, phyllosilicates, ice free surface, nanophase or crystalline ferric oxides, dust- and ice-free mafic } \\
\text { surface (Figure 11) }\end{array}$ \\
\hline 3 & Eastern Hale Crater & $\begin{array}{l}\text { Nanophase or crystalline ferric oxides, chlorides, hydrated mineral (phyllosilicates), water ice or frost, ice-free and more mafic } \\
\text { surface (Figure 12) }\end{array}$ \\
\hline 4 & Northern Hale Crater & Chlorides, phyllosilicates (traces), ice-free surface, nanophase ferric oxides, dust-free mafic surface (Figure 13) \\
\hline
\end{tabular}

RSL sites could be habitable (Maus et al., 2020). Other temperature or season-dependent factors may influence sand movement and contribute to RSL seasonality. It is possible that local heating of slopes plays an important role in outcrop scale wind patterns. For RSL, in particular, it may be necessary to resolve the effects of topography at the scale of outcrops and local slopes (Newman et al., 2017). Additionally, temperature changes could influence the cohesion of sand, for instance, due to variations in the amount of adsorbed water (McEwen et al., 2011; Dundas et al., 2017).

The reported data and observations in the current paper could strengthen the hypothesis that the Asimov crater's RSL formation is because of wet surface or subsurface deliquescence processes. Other observations reported in the literature are also in line; for example, the surface temperatures corresponding to RSL activity are above the freezing points for salty solutions, which can be as 
low as $200 \mathrm{~K}$ (Möhlmann and Thomsen, 2011; Martínez and Renno, 2013). However, explaining the source of sufficient water for seepage is extremely difficult in the present-day Martian environment (Mellon and Phillips, 2001; Dundas et al., 2017).

A previous observation by Nuding et al. (2019) shows that, with the increase in relative humidity increases, visual growth and darkening are observed, which are caused by increases in water uptake, also are confirmed by Raman spectroscopy equipped with an environmental cell (Nuding et al., 2019), which can be considered as one of the trigger mechanisms for RSL. In the Asimov crater, the surface temperature $(\mathrm{K})$ and water vapor column observed to be increased from $158 \mathrm{k}$ to $261 \mathrm{~K}$ (inside crater) consistently increased in water-vapor five times in the crater, which indicates regolith-atmosphere interaction and high deliquescence potential in the surface and subsurface, and it also suggests an active water cycle.

The RSL activity in the Hale crater and associated atmospheric parameters show the temperature to be increased and water vapor column. Previously studied results from thermal analysis establish that local temperatures are observed to be high enough to allow either the melting of brines or deliquescence of salts during the observation period. However, the slope and aspect distributions of RSL activity predicted for these processes are not consistent with the observations in the Hale crater, which is also seen in the current study. There was no significant relative albedo difference, which suggests that RSL at Hale crater are not caused by seeping water that reaches the surface, but are best explained by other hypothesis and mainly by dry flows of granular material. Ojha et al. (2015) detect temporally and spatially initial change in surface hydration linked with RSL activity. Perchlorates (chlorate) in situ presence on the surface of Mars is also confirmed at the Phoenix landing site, where visible water ice was also found (Chevrier et al., 2007). Recent evidence of perchlorates at RSL sites strengthens the hypothesis that at least some RSL are produced by liquid water flow (Mitchell and Christensen, 2016). The variations in RSL as the formation of liquid brine (water uptake with the increase of relative humidity) and calcium perchlorate particles undergo visual transformations as the relative humidity increases in the presence of water uptake. Heinz et al. (2016) report that highly deliquescent salts are known to exist on Mars and may temporarily trap atmospheric water in extremely small quantities, perhaps sufficient to darken the surface but not sufficient for seepage down slopes (Gough et al., 2019; Nuding et al., 2019). Some workers have speculated that small quantities of water could trigger granular flows [ 44,63].

MarsWRF experimental simulations found that perchlorate and other salts in RSL could potentially form liquid brine via deliquescence with suitable environmental conditions (temperature, water vapor) (Nuding et al., 2019). MarsWRF (Toigo et al., 2012) is a numerical Martian atmospheric model explicitly simulating dynamical processes and parameterizing unresolved processes (e.g., radiative transfer, atmospheric phase changes, etc.). During those analyses, calcium perchlorate particles demonstrate water uptake and loss (Nuding et al., 2019). To understand the water uptake properties of calcium perchlorate at RSL locations, Raman microscope equipped with an environmental cell is used (Nuding et al., 2019). In their experiment, the Raman spectra indicate that water uptake is occurring as relative humidity is increased. Additionally, the calcium perchlorate particles undergo visual transformations (growth and darkening) as the relative humidity is increased, and the presence of water uptake is confirmed by Raman spectroscopy (Nuding et al., 2019), which supports the theory of deliquescence as one of mechanism for the regolith-atmosphere interaction and RSL formation.

In the future, spatial and spectral high-resolution analyses of RSL sites will help to ascertain whether the origin and formation of RSL is a singular process on a global scale or instead consists of a range of processes. As RSL are found at many latitudes and geologic environments on Mars, it is possible that a range of RSL formation mechanisms exists. From the observations in this study, alternative hypotheses for RSL formation that do not involve significant surface or subsurface deliquescence of liquid flow should be further explored. Likewise, without the existence of significant amounts of brine, capillary wicking of brines to the surface may account for the apparent darkening of the surface (Grimm et al., 2014). In addition, granular flow due to lubrication of grains by a thin film of water (Möhlmann and Kereszturi, 2010; McEwen et al., 2011) is considered more plausible due to the relatively low demand of resources needed to initiate it.

\section{CONCLUSION}

In this work, we analyzed HiRISE, CRISM, CTX, and MOLA data to perform detailed geo-morphological and compositional analysis of the Hale and Asimov craters along with a detailed atmospheric analysis with the aim to investigate the origin of RSL present in these craters. A total of 940 candidate and confirmed RSL sites were mapped using previous literature and newly identified sites globally on Mars. The study concludes that, in Asimov crater, local temperatures are high enough to allow either the melting of brines or the deliquescence of salts during the HiRISE observation period because water vapor column values are observed to be nearly five times those measured before RSL appearance in the image as well as the slope and aspect distributions are consistent with the observations. This marked increase in water vapor indicates the possibility of surficial or subsurface deliquescence. Furthermore, the possible local cyclical interaction between the atmosphere and regolith could be described as the Martian water cycle. The composition of Asimov crater is found to be coarse-grained $\mathrm{Fe}$, particularly low-calcium pyroxene. Nanophase or crystalline ferric oxides are also present in traces. Along with hydrated mineralogy (phyllosilicates), chlorides are also observed. In the eastern Asimov crater, traces of $\mathrm{CO}_{2}$ frost are also found, whereas water ice frost is observed in the southwest of Asimov crater where RSL sites exist. The surface is dust- and ice-free with more mafic content. In Hale crater, the slope and aspect distributions of RSL activity predicted are not consistent with observations. Based on the CRISM RGB band combination, the area was dust- and 
ice-free. However, the surround could have some ice. The investigated scene is observed to have a more mafic area, which is free of dust, hence dust not triggering the RSL appearance in the area.

The noted earlier finding suggests that RSL at Hale crater are not produced by seeping water, but are best explained by other hypothesis and mainly by dry flows of granular material. Hale crater is mostly composed of nanophase or crystalline ferric oxides along with chlorides and hydrated minerals. It also has water ice or frost and indicates the surface as dust- and ice-free and more mafic. Previous experimental study by researchers using the MarsWRF model also supports the theory of deliquescence as a major mechanism for the regolithatmosphere interaction and RSL formation, which suggests that minerals absorb moisture from the environment until the minerals dissolve in the absorbed water and yield a solution, which is also supporting the current study.

\section{DATA AVAILABILITY STATEMENT}

The original contributions presented in the study are included in the article/Supplementary Material, further inquiries can be directed to the corresponding author.

\section{REFERENCES}

Abotalib, A. Z., and Heggy, E. (2019). A Deep Groundwater Origin for Recurring Slope Lineae on Mars. Nat. Geosci. 12, 235-241. doi:10.1038/s41561-019032710.1038/s41561-019-0327-5

Bhardwaj, A., Sam, L., Martín-Torres, F. J., and Zorzano, M.-P. (2019). Discovery of Recurring Slope Lineae Candidates in Mawrth Vallis, Mars. Sci. Rep. 9, 2040. doi:10.1038/s41598-019-39599-z

Cantor, B. A., Kanak, K. M., and Edgett, K. S. (2006). Mars Orbiter Camera Observations of Martian Dust Devils and Their Tracks (September 1997 to January 2006) and Evaluation of Theoretical Vortex Models. J. Geophys. Res. Planets 111 (E12). doi:10.1029/2006je002700

Carter, J., Poulet, F., Bibring, J.-P., Mangold, N., and Murchie, S. (2013). Hydrous Minerals on Mars as Seen by the CRISM and OMEGA Imaging Spectrometers: Updated Global View. J. Geophys. Res. Planets 118, 831-858. doi:10.1029/ 2012je004145

Chevrier, V. F., and Rivera-Valentin, E. G. (2012). Formation of Recurring Slope Lineae by Liquid Brines on Present-day Mars. Geophys. Res. Lett. 39 (21), L21202. doi:10.1029/2012gl054119

Chevrier, V., Sears, D. W. G., Chittenden, J. D., Roe, L. A., Ulrich, R., BrysonBillingsley, K. L., et al. (2007). Sublimation Rate of Ice under Simulated Mars Conditions and the Effect of Layers of Mock Regolith JSC Mars-1. Geophys. Res. Lett. 34, L02203. doi:10.1029/2006GL028401

Christensen, P. R., Jakosky, B. M., Kieffer, H. H., Malin, M. C., Jr, H. Y. M., Nealson, K., et al. (2004). The Thermal Emission Imaging System (THEMIS) for the Mars 2001 Odyssey Mission. Space Sci. Rev. 110 (1/2), 85-130. doi:10.1007/9780-306-48600-5_3

Clark, R. N., and Roush, T. L. (1984). Reflectance Spectroscopy: Quantitative Analysis Techniques for Remote Sensing Applications. J. Geophys. Res. 89 (B7), 6329-6340. doi:10.1029/JB089iB07p06329

Costard, F., Forget, F., Mangold, N., and Peulvast, J. P. (2002). Formation of Recent Martian Debris Flows by Melting of Near-Surface Ground Ice at High Obliquity. Science 295, 110-113. doi:10.1126/science.1066698

Dundas, C. M., McEwen, A. S., Chojnacki, M., Milazzo, M. P., Byrne, S., McElwaine, J. N., et al. (2017). Granular Flows at Recurring Slope Lineae

\section{AUTHOR CONTRIBUTIONS}

Supervision, FH; writing - original draft preparation, FH and MS; writing-review and editing, FH and MS; Conceptualization, MS; methodology, MS; Formal analysis, MS; software, MS; validation, $\mathrm{FH}, \mathrm{MS}, \mathrm{CX}$, and YN; investigation, MS; visualization, MS; funding acquisition, FH, FA.

\section{ACKNOWLEDGMENTS}

The authors would like to extend our thanks and appreciation to Zayed University, Abu Dhabi, for providing the facility to carry out the research. The authors would like to thank Prof James Terry for reviewing and editing this manuscript. The authors would like to extend our thanks and appreciation to UAE Space Agency for funding this research Z01-2016-001.

\section{SUPPLEMENTARY MATERIAL}

The Supplementary Material for this article can be found online at: https://www.frontiersin.org/articles/10.3389/fspas.2021.781166/ full\#supplementary-material

on Mars Indicate a Limited Role for Liquid Water. Nat. Geosci 10 (12), 903-907. doi:10.1038/s41561-017-0012-5

Edwards, C. S., and Piqueux, S. (2016). The Water Content of Recurring Slope Lineae on Mars. Geophys. Res. Lett. 43 (17), 8912-8919. doi:10.1002/ 2016gl070179

Ehlmann, B. L., and Edwards, C. S. (2014). Mineralogy of the Martian Surface. Annu. Rev. Earth Planet. Sci. 42, 291-315. doi:10.1146/annurev-earth-060313055024

Ehlmann, B. L., Mustard, J. F., Murchie, S. L., Poulet, F., Bishop, J. L., Brown, A. J., et al. (2008). Orbital Identification of Carbonate-Bearing Rocks on Mars. Science 322 (5909), 1828-1832. doi:10.1126/science.1164759

Fischer, E., Martínez, G. M., Elliott, H. M., and Rennó, N. O. (2014). Experimental Evidence for the Formation of Liquid saline Water on Mars. Geophys. Res. Lett. 41, 4456-4462. doi:10.1002/2014gl060302

Francois, F., Hourdin, F., Fournier, R., Hourdin, C., Talagrand, O., Collins, M., et al. (1999). Improved General Circulation Models of the Martian Atmosphere from the Surface to above $80 \mathrm{Km}$. J. Geophys. Res. 104 (E10), 24155-24175.

Goudge, T. A., Mustard, J. F., Head, J. W., Fassett, C. I., and Wiseman, S. M. (2015). Assessing the Mineralogy of the Watershed and Fan Deposits of the Jezero Crater Paleolake System, Mars. J. Geophys. Res. Planets 120, 4. doi:10.1002/ 2014je004782

Gough, R. V., Chevrier, V. F., Baustian, K. J., Wise, M. E., and Tolbert, M. A. (2011). Laboratory Studies of Perchlorate Phase Transitions: Support for Metastable Aqueous Perchlorate Solutions on Mars. Earth Planet. Sci. Lett. 312, 371-377. doi:10.1016/j.epsl.2011.10.026

Gough, R. V., Primm, K. M., Rivera-Valentín, E. G., Martínez, G. M., and Tolbert, M. A. (2019). Solid-solid Hydration and Dehydration of Mars-relevant Chlorine Salts: Implications for Gale Crater and RSL Locations. Icarus 321, 1-13. doi:10.1016/j.icarus.2018.10.034

Grant, J. A., Irwin, R. P., Grotzinger, J. P., Milliken, R. E., Tornabene, L. L., McEwen, A. S., et al. (2008). HiRISE Imaging of Impact Megabreccia and Submeter Aqueous Strata in Holden Crater, Mars. Geol 36, 195-198. doi:10.1130/ g24340a.1

Grimm, R. E., Harrison, K. P., and Stillman, D. E. (2014). Water Budgets of Martian Recurring Slope Lineae. Icarus 233, 316-327. doi:10.1016/ j.icarus.2013.11.013 
Heinz, J., Schulze-Makuch, D., and Kounaves, S. P. (2016). Deliquescence-induced Wetting and RSL-like Darkening of a Mars Analogue Soil Containing Various Perchlorate and Chloride Salts. Geophys. Res. Lett. 43 (10), 4880-4884. doi:10.1002/2016gl068919

Herrick, R. R., and Hessen, K. K. (2006). The Planforms of Low-Angle Impact Craters in the Northern Hemisphere of Mars. Meteorol. Planet. Sci. 41 (10), 1483-1495. doi:10.1111/j.1945-5100.2006.tb00431.x

H. Hargitai and Á. Kereszturi (Editors) (2015). Encyclopedia of Planetary Landforms (Amsterdam, Netherlands: Springer).

Howari, F. M., Sharma, M., Nazzal, Y., AlAydaroos, F., and Xavier, C. M. (2020). Atmospheric and Topographic Analysis of Mars. Proceedings of the 51st Lun. Planet. Sci., Houston, TX, February 2020. Abstract 1263.

Howari, F. M., Sharma, M., Xavier, C. M., Nazzal, Y., and AlAydaroos, F. (2021). Chronological Analysis and Remote Sensing of Craters on the Surface of Mars. Front. Environ. Sci. 9. doi:10.3389/fenvs.2021.605893

Jones, A. P., McEwen, A. S., Tornabene, L. L., Baker, V. R., Melosh, H. J., and Berman, D. C. (2011). A Geomorphic Analysis of Hale Crater, Mars: The Effects of Impact into Ice-Rich Crust. Icarus 211, 259-272. doi:10.1016/ j.icarus.2010.10.014

Kass, D. M., Kleinböhl, A., McCleese, D. J., Schofield, J. T., and Smith, M. D. (2016). Interannual Similarity in the Martian Atmosphere during the Dust Storm Season. Geophys. Res. Lett. 43 (12), 6111-6118. doi:10.1002/2016gl068978

Lemmon, M. T., Wolff, M. J., Bell, J. F., III, Smith, M. D., Cantor, B. A., and Smith, P. H. (2015). Dust Aerosol, Clouds, and the Atmospheric Optical Depth Record over 5 Mars Years of the Mars Exploration Rover mission. Icarus 251, 96-111. doi:10.1016/j.icarus.2014.03.029

Leung, C. W. S., and Rafkin, S. C. R. (2015). Mesoscale Atmospheric Modeling of Water Vapor in Valles Marineris. Lun. Planet. Sci., 2959.

Levy, J. (2012). Hydrological Characteristics of Recurrent Slope Lineae on Mars: Evidence for Liquid Flow through Regolith and Comparisons with Antarctic Terrestrial Analogs. Icarus 219 (1), 1-4. doi:10.1016/j.icarus.2012.02.016

Malin, M. C., Bell, J. F., Calvin, W. M., and Cantor, B. A. (2007). "Initial Observations by the MRO Mars Color Imager and Context Camera," in Proceedings of the Lun. Planet. Sci., At: Houston Texas USA, March 2007, 2068.

Malin, M. C., and Edgett, K. S. (2001). Mars Global Surveyor Mars Orbiter Camera: Interplanetary Cruise through Primary mission. J. Geophys. Res. 106 (E10), 23429-23570. doi:10.1029/2000je001455

Martínez, G. M., and Renno, N. O. (2013). Water and Brines on Mars: Current Evidence and Implications for MSL. Space Sci. Rev. 175 (1-4), 29-51. doi:10.1007/s11214-012-9956-3

Maus, D., Heinz, J., Schirmack, J., Airo, A., Kounaves, S. P., Wagner, D., et al. (2020). Methanogenic Archaea Can Produce Methane in Deliquescence-Driven Mars Analog Environments. Sci. Rep. 10 (1), 6-7. doi:10.1038/s41598-01956267-4

McEwen, A. S. (2015). Recurring Slope Lineae on Mars: Atmospheric Origin? Eur. Planet. Sci. 10, 786.

McEwen, A. S. (2018). “Are Recurring Slope Lineae Habitable? From Habitability to Life on Mars (Amsterdam, Netherlands: Elsevier), 249-274. doi:10.1016/ b978-0-12-809935-3.00008-6

McEwen, A. S., Dundas, C. M., Mattson, S. S., Toigo, A. D., Ojha, L., Wray, J. J., et al. (2014). Recurring Slope Lineae in Equatorial Regions of Mars. Nat. Geosci 7 (1), 53-58. doi:10.1038/ngeo2014

McEwen, A. S., Ojha, L., Dundas, C. M., Mattson, S. S., Byrne, S., Wray, J. J., et al. (2011). Seasonal Flows on Warm Martian Slopes. Science 333, 740-743. doi:10.1126/science.1204816

Mellon, M. T., and Jakosky, B. M. (1995). The Distribution and Behavior of Martian Ground Ice during Past and Present Epochs. J. Geophys. Res. 100, 11781-11799. doi:10.1029/95je01027

Mellon, M. T., and Phillips, R. J. (2001). Recent Gullies on Mars and the Source of Liquid Water. J. Geophys. Res. 106 (E10), 23165-23179. doi:10.1029/ 2000je001424

Melosh, H. J. (1989). Impact Cratering: A Geologic Process. New York, NY: Oxford University Press.

Millour, E., Forget, F., Spiga, A., Vals, M., Zakharov, V., Montabone, L., et al. (2018). MCD Development Team. THE MARS CLIMATE DATABASE (VERSION 5.3). Scientific Workshop: "From Mars Express to ExoMars".

Ming, D. W., Archer, P. D., Jr., Glavin, D. P., Eigenbrode, J. L., Franz, H. B., Sutter, B., et al. (2014). Volatile and Organic Compositions of Sedimentary Rocks in
Yellowknife Bay, Gale Crater, Mars. Science 343, 1245267. doi:10.1126/ science. 1245267

Mitchell, J. L., and Christensen, P. R. (2016). Recurring Slope Lineae and Chlorides on the Surface of Mars. J. Geophys. Res. Planets 121, 1411-1428. doi:10.1002/ 2016je005012

Möhlmann, D., and Kereszturi, A. (2010). Viscous Liquid Film Flow on Dune Slopes of Mars. Icarus 207 (2), 654-658. doi:10.1016/j.icarus.2010.01.002

Möhlmann, D., and Thomsen, K. (2011). Properties of Cryobrines on Mars. Icarus 212 (1), 123-130. doi:10.1016/j.icarus.2010.11.025

Morgan, G. A., Head, J. W., and Marchant, D. R. (2011). Preservation of Late Amazonian Mars Ice and Water-Related Deposits in a Unique Crater Environment in Noachis Terra: Age Relationships between Lobate Debris Tongues and Gullies. Icarus 211, 347-365. doi:10.1016/j.icarus.2010.08.004

Munaretto, G., Pajola, M., Cremonese, G., Re, C., Lucchetti, A., Simioni, E., et al. (2020). Implications for the Origin and Evolution of Martian Recurring Slope Lineae at Hale Crater from CaSSIS Observations. Planet. Space Sci. 187, 104947. doi:10.1016/j.pss.2020.104947

Murchie, S. (2007). Compact Reconnaissance Imaging Spectrometer for Mars (CRISM) on Mars Reconnaissance Orbiter (MRO). J. Geophys. Res. 112, E05S03.

Mustard, J. F., Murchie, S. L., Pelkey, S. M., Ehlmann, B. L., Milliken, R. E., Grant, J. A., et al. (2008). Hydrated Silicate Minerals on Mars Observed by the Mars Reconnaissance Orbiter CRISM Instrument. Nature 454 (7202), 305-309. doi:10.1038/nature07097

Newman, C. E., Gómez-Elvira, J., Marin, M., Navarro, S., Torres, J., Richardson, M. I., Battalio, J. M., Guzewich, S. D., Sullivan, R., Torre, M. d. l., Vasavada, A. R., and Bridges, N. T. (2017). Winds Measured by the Rover Environmental Monitoring Station (REMS) during the Mars Science Laboratory (MSL) Rover's Bagnold Dunes Campaign and Comparison with Numerical Modeling Using MarsWRF. Icarus 291, 203-231. doi:10.1016/j.icarus.2016.12.016

Nikolakakos, G., and Whiteway, J. A. (2015). Laboratory Investigation of Perchlorate Deliquescence at the Surface of Mars with a Raman Scattering Lidar. Geophys. Res. Lett. 42, 7899-7906. doi:10.1002/2015gl065434

Nuding, D. L., Gough, R. V., Toigo, A., Guzewich, S., and Tolbert, M. A. (2019). An Examination of Atmospheric Water Vapor as a Source for Recurring Slope Lineae on Mars. 50th Lunar Planet. Sci. (3113). Abstract.

Nuding, D. L., Davis, R. D., Gough, R. V., and Tolbert, M. A. (2015). The Aqueous Stability of a Mars Salt Analog: Instant Mars. J. Geophys. Res. Planets 120, 588-598. doi:10.1002/2014je004722

Nuding, D. L., Rivera-Valentin, E. G., Davis, R. D., Gough, R. V., Chevrier, V. F., and Tolbert, M. A. (2014). Deliquescence and Efflorescence of Calcium Perchlorate: An Investigation of Stable Aqueous Solutions Relevant to Mars. Icarus 243, 420-428. doi:10.1016/j.icarus.2014.08.036

Oberbeck, V. R., and Morrison, R. H. (1973). On the Formation of Lunar Herringbone Pattern Lunar Planet. Sci IV (1), 107-123.

Ojha, L., McEwen, A., Dundas, C., Byrne, S., Mattson, S., Wray, J., et al. (2014). HiRISE Observations of Recurring Slope Lineae (RSL) during Southern Summer on Mars. Icarus 231, 365-376. doi:10.1016/j.icarus.2013.12.021

Ojha, L., Wilhelm, M. B., Murchie, S. L., McEwen, A. S., Wray, J. J., Hanley, J., et al. (2015). Spectral Evidence for Hydrated Salts in Recurring Slope Lineae on Mars. Nat. Geosci 8 (11), 829-832. doi:10.1038/ngeo2546

Pál, B., and Kereszturi, Á. (2020). Annual and Daily Ideal Periods for Deliquescence at the landing Site of InSight Based on GCM Model Calculations. Icarus 340, 113639. doi:10.1016/j.icarus.2020.113639

Rafkin, S. C. R., Stillman, D. E., and McEwen, A. S. (2016). "Fogs and Clouds Are a Potential Indicator of Local Water Source in Valles Marineris," in ., 2878.Lunar Planet. Sci.

Rivera-Valentín, E. G., Chevrier, V. F., Soto, A., and Martínez, G. (2020). Distribution and Habitability of (Meta)stable Brines on Present-Day Mars. Nat. Astron. 4 (8), 756-761. doi:10.1038/s41550-020-1080-9

Runyon, K., and Ojha, L. (2014). "Recurring Slope Lineae," in Encyclopedia of Planetary Landforms. Editors H. Hargitai and Á. Kereszturi (New York: Springer), 1-6. doi:10.1007/978-1-4614-9213-9_352-1

Schorghofer, N., and Aharonson, O. (2005). Stability and Exchange of Subsurface Ice on Mars. J. Geophys. Res. Planets 110 (E5). doi:10.1029/2004je002350

Scott, D. H., and Carr, M. H. (1978). Geologic Map of Mars. U.S. Geol. Surv. Misc. Invest. Set. Map, 1-1083.

Smith, D. E., Zuber, M. T., Solomon, S. C., Phillips, R. J., Head, J. W., Garvin, J. B., et al. (1999). The Global Topography of Mars and Implications 
for Surface Evolution. Science 284, 1495-1503. doi:10.1126/ science.284.5419.1495

Smith, M. D., Daerden, F., Neary, L., and Khayat, A. (2018). The Climatology of Carbon Monoxide and Water Vapor on Mars as Observed by CRISM and Modeled by the GEM-Mars General Circulation Model. Icarus 301, 117-131. doi:10.1016/j.icarus.2017.09.027

Soderblom, L. A. (1992). The Composition and Mineralogy of the Martian Surface from Spectroscopic Observations: $0.3 \mu \mathrm{m}$ to $50 \mu \mathrm{m}$. Mars, 557-593. (A93-27852 09-91).

Stillman, D. E., Michaels, T. I., and Grimm, R. E. (2017). Characteristics of the Numerous and Widespread Recurring Slope Lineae (RSL) in Valles Marineris, Mars. Icarus 285, 195-210. doi:10.1016/j.icarus.2016.10.025

Stillman, D. E., Michaels, T. I., Grimm, R. E., and Hanley, J. (2016). Observations and Modeling of Northern Mid-latitude Recurring Slope Lineae (RSL) Suggest Recharge by a Present-Day Martian Briny Aquifer. Icarus 265, 125-138. doi:10.1016/j.icarus.2015.10.007

Stillman, D. E., Michaels, T. I., Grimm, R. E., and Harrison, K. P. (2014). New Observations of Martian Southern Mid-latitude Recurring Slope Lineae (RSL) Imply Formation by Freshwater Subsurface Flows. Icarus 233, 328-341. doi:10.1016/j.icarus.2014.01.017

Toigo, A. D., Lee, C., Newman, C. E., and Richardson, M. I. (2012). The Impact of Resolution on the Dynamics of the Martian Global Atmosphere: Varying Resolution Studies with the MarsWRF GCM. Icarus 221, 276-288. doi:10.1016/j.icarus.2012.07.020

Viviano, C. E., Seelos, F. P., Murchie, S. L., Kahn, E. G., Seelos, K. D., Taylor, H. W., et al. (2014). Revised CRISM Spectral Parameters and Summary Products Based on the Currently Detected mineral Diversity on Mars. J. Geophys. Res. Planets 119 (6), 1403-1431. doi:10.1002/2014je004627

Wray, J. J., Murchie, S. L., Ehlmann, B. L., Milliken, R. E., Seelos, K. D., Noe Dobrea, E. Z., et al. (2011). Evidence for Regional Deeply Buried Carbonate-Bearing Rocks on Mars. Lunar Planet. Sci. No. 1608, 2635

Zorzano, M.-P., Mateo-Martí, E., Prieto-Ballesteros, O., Osuna, S., and Renno, N. (2009). Stability of Liquid Saline Water on Present Day Mars. Geophys. Res. Lett. 36 (20).

Conflict of Interest: The authors declare that the research was conducted in the absence of any commercial or financial relationships that could be construed as a potential conflict of interest.

Publisher's Note: All claims expressed in this article are solely those of the authors and do not necessarily represent those of their affiliated organizations, or those of the publisher, the editors and the reviewers. Any product that may be evaluated in this article, or claim that may be made by its manufacturer, is not guaranteed or endorsed by the publisher.

Copyright (C) 2022 Howari, Sharma, Xavier, Nazzal and Alaydaroos. This is an openaccess article distributed under the terms of the Creative Commons Attribution License (CC BY). The use, distribution or reproduction in other forums is permitted, provided the original author(s) and the copyright owner(s) are credited and that the original publication in this journal is cited, in accordance with accepted academic practice. No use, distribution or reproduction is permitted which does not comply with these terms. 